\title{
Porphyrazines as Molecular Scaffolds: Flexible Syntheses of Novel Multimetallic Complexes
}

Tomasz Goslinski, ${ }^{\dagger}$ Chang Zhong, ${ }^{*}$ Matthew J. Fuchter, ${ }^{\dagger}$ Charlotte L. Stern, ${ }^{*}$ Andrew J.P. White,,$^{\dagger}$ Anthony G.M. Barrett $t^{t^{*}}$ and Brian M. Hoffman ${ }^{t^{*}}$

\section{Supporting Information}

\section{Table of Contents}

General Experimental Procedures: S-1

${ }^{1} \mathrm{H} /{ }^{13} \mathrm{C}$ NMR compound 3a: $\mathrm{S}-2$

${ }^{1} \mathrm{H} /{ }^{13} \mathrm{C}$ NMR compound 3b: S-4

${ }^{1}$ H NMR compound 8: S-6

${ }^{1} \mathrm{H} /{ }^{13} \mathrm{C}$ NMR compound 13: S-7

${ }^{1} \mathrm{H} /{ }^{13} \mathrm{C}$ NMR compound 14a: S-9

${ }^{1}$ H NMR compound 14b: S-11

${ }^{1}$ H NMR compound 15a: S-12

${ }^{1}$ H NMR compound 15b: S-13

X-ray crystallographic data compounds 3a, 3b, 8, 14a, 14b, 18a, 20: S-14 


\section{General Procedures.}

All reactions were conducted in oven dried glassware under $\mathrm{N}_{2}$. Reaction temperatures reported refer to external bath temperatures. Pyridine was distilled from $\mathrm{CaH}_{2}$. Other solvents and all reagents were obtained from commercial suppliers and used without further purification unless otherwise stated. All chromatography was carried out on silica (eluants are given in parenthesis). Thin layer chromatography (TLC) was performed on glass backed silica plates and visualised with UV ( $\lambda_{\max } 254$ $\mathrm{nm})$. All solvents were rotary evaporated at or below $50{ }^{\circ} \mathrm{C}$ under reduced pressure except for solvent DMF and pyridine, which were removed by distillation below 50 ${ }^{\circ} \mathrm{C}$ at 0.15 mbar at $\mathrm{mmHg}$.

Electrochemistry. Cyclic voltammetry data were recorded with a Cypress Systems 2000 computer-controlled potentiostat. A three electrode configuration was employed: a platinum disk working electrode, a silver wire counter electrode, and a silver-silver chloride reference electrode. Measurements were made in $\mathrm{CH}_{2} \mathrm{Cl}_{2}$, freshly distilled from $\mathrm{CaH}_{2}$, with $\mathrm{Bu}_{4} \mathrm{NPF}_{6}$ as the supporting electrolyte. All measurements were calibrated by addition of ferrocene as an internal reference and $E_{1 / 2}$ values were calculated from $\left(E_{\mathrm{pa}}+E_{\mathrm{pc}}\right) / 2$ at a scan rate of $110 \mathrm{mVs}^{-1}$.

X-Ray Structure Determinations. X-Ray crystallographic structure determinations were carried out using Oxford Diffraction Xcalibur 3 (3a, 14a and 14a·2py), PX Ultra (3b, 14b, 18a and 20) and Bruker SMART-1000 CCD (8) diffractometers, and the structures were refined based on $F^{2}$ using the SHELXTL, SHELX-90 and SHELX-97 program systems. 


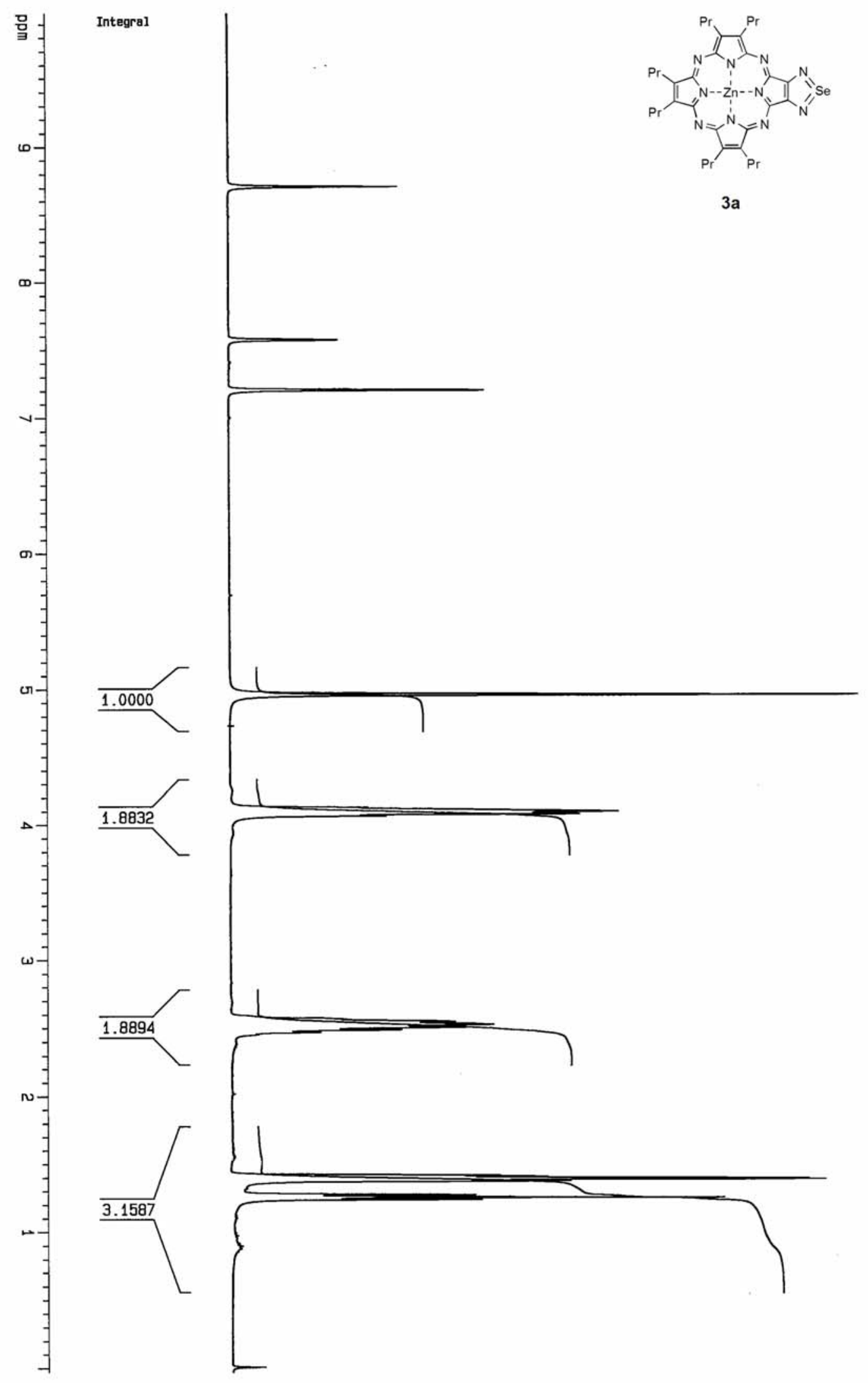




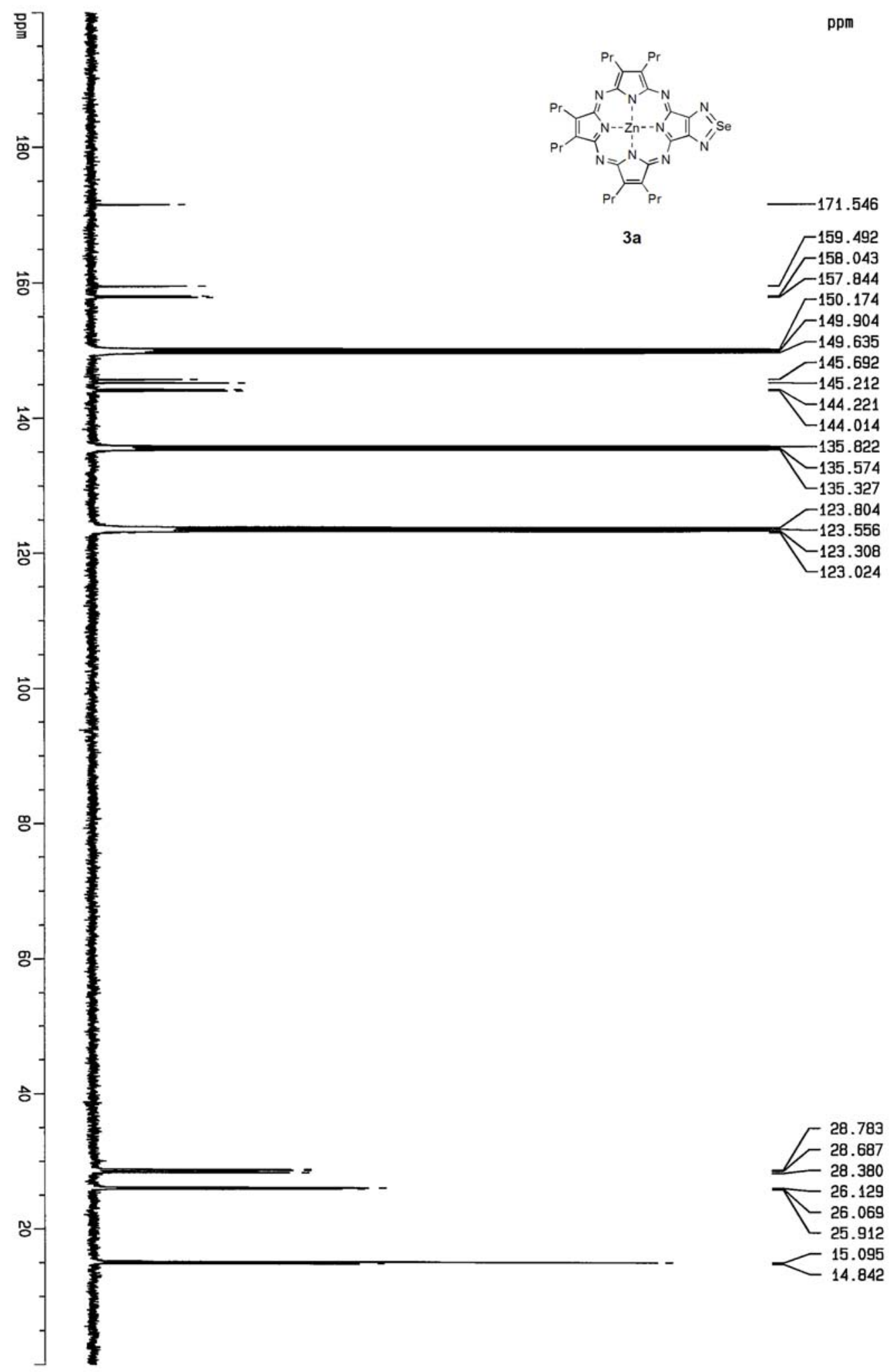




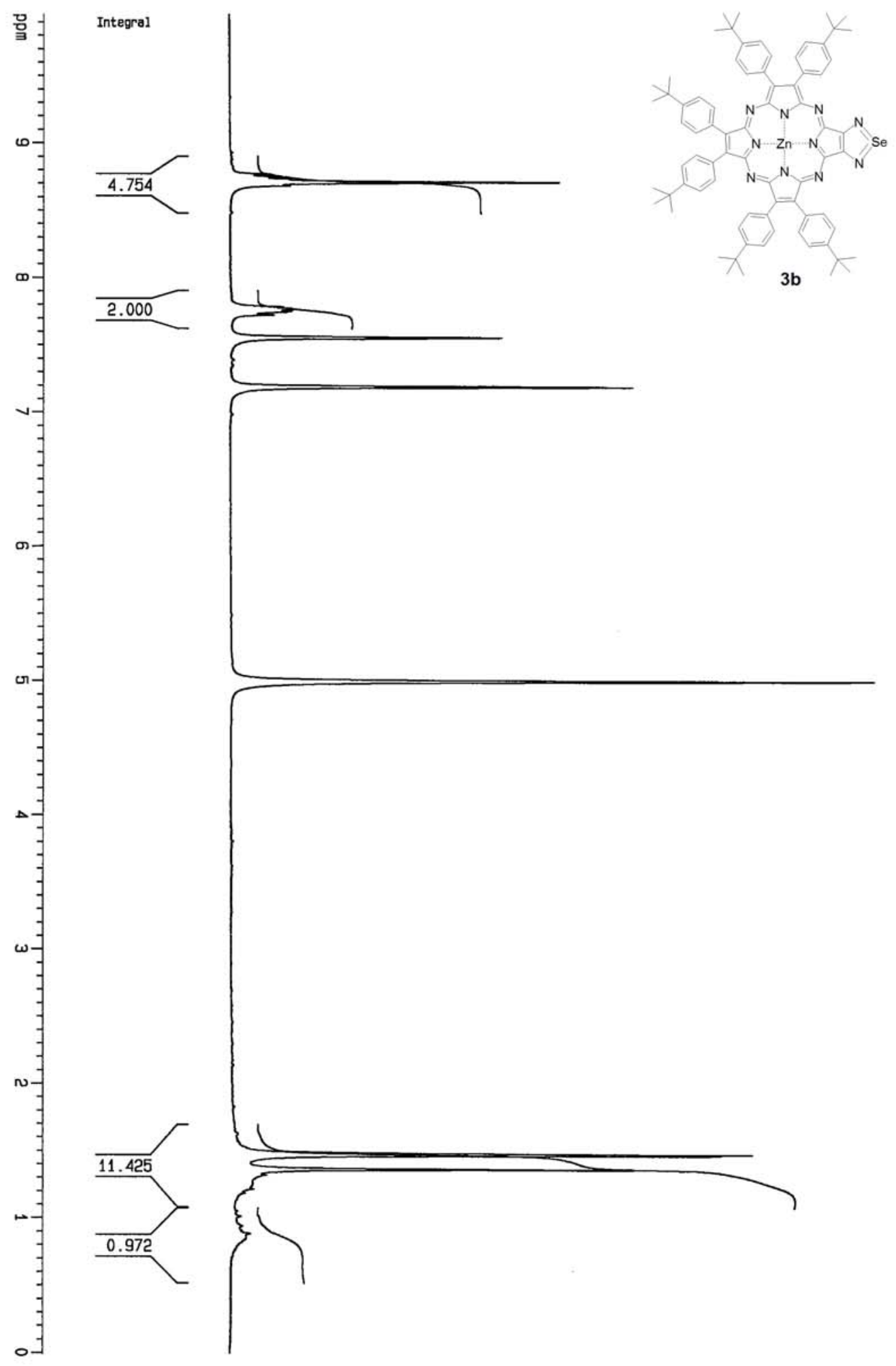




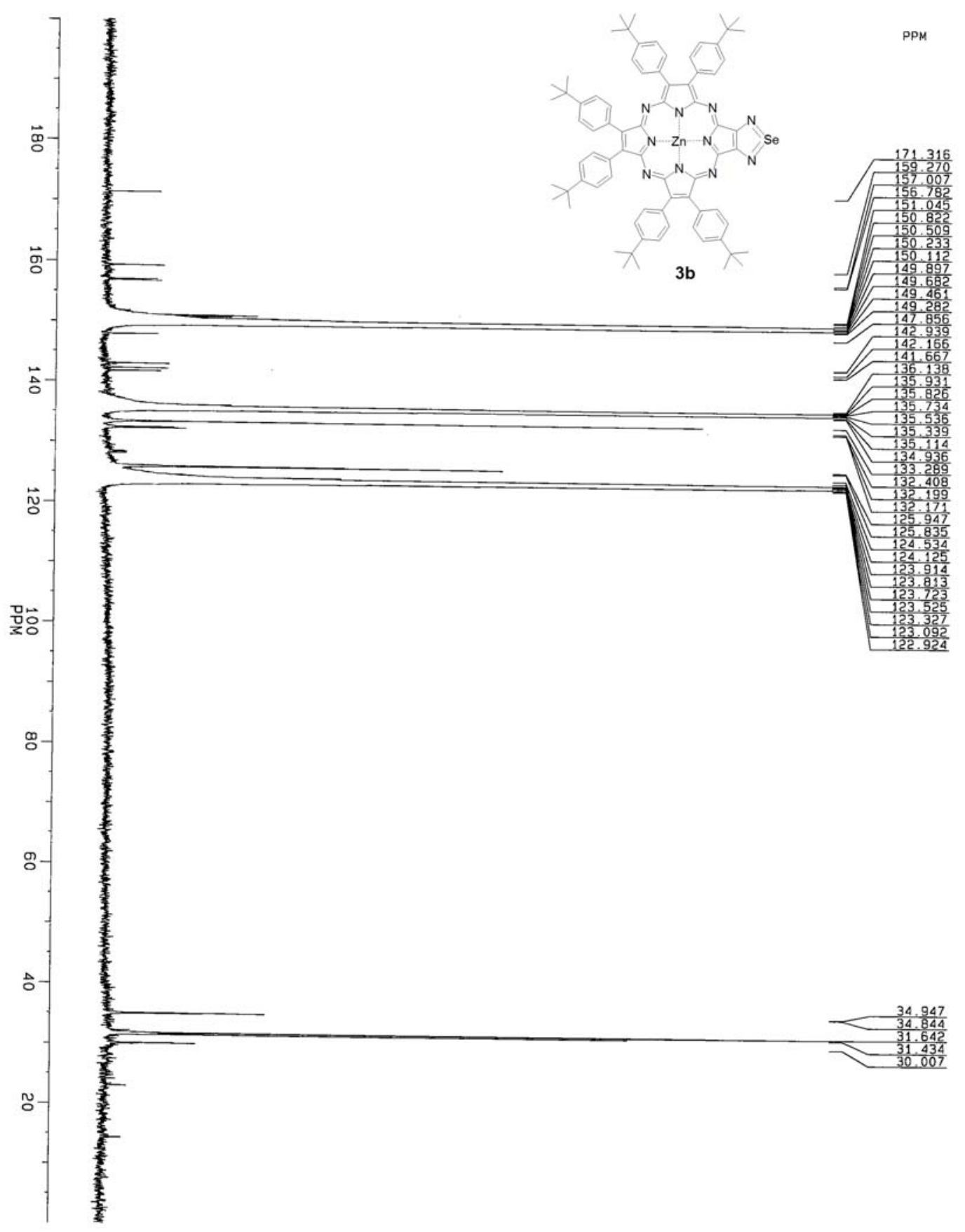




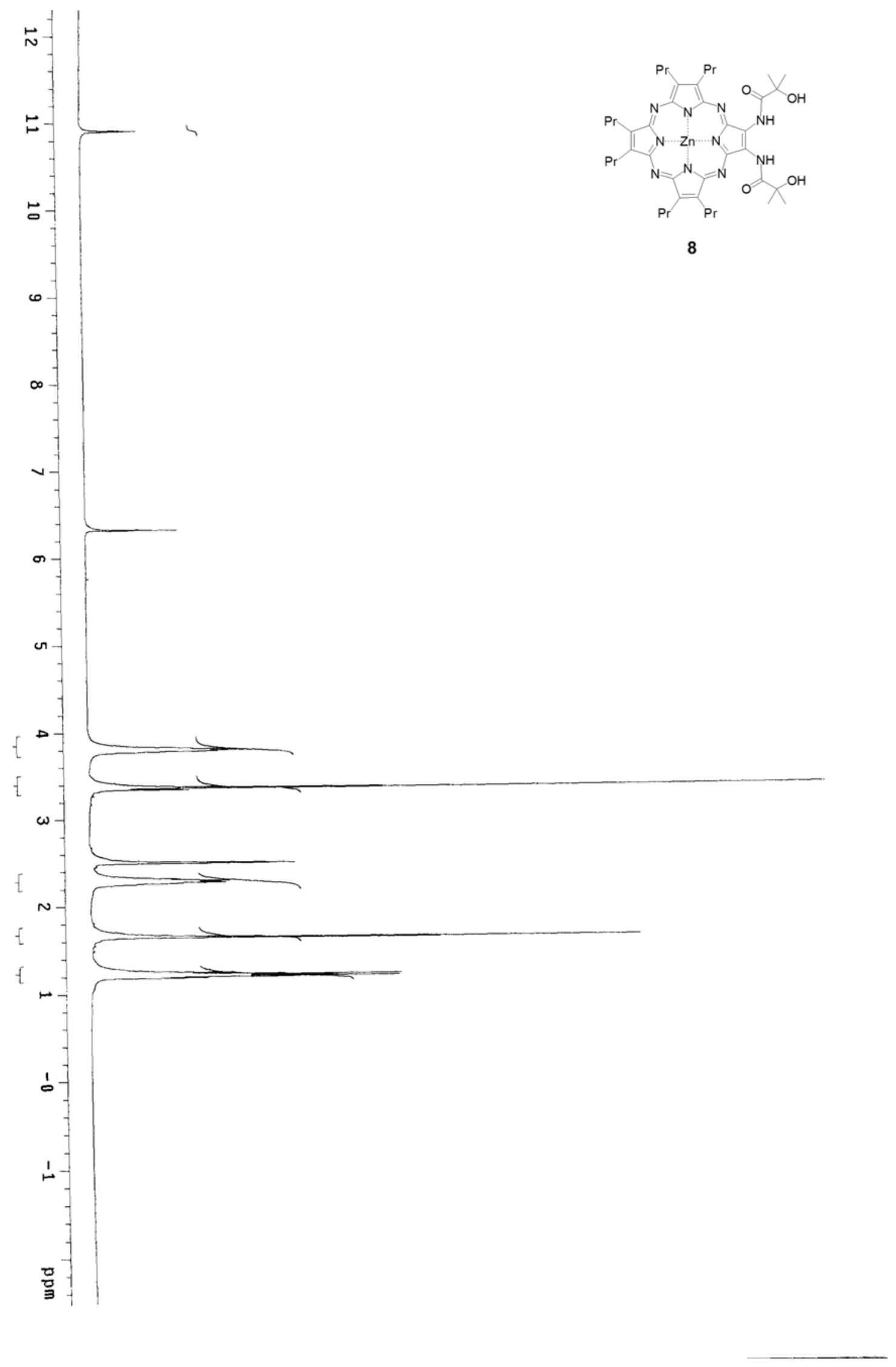

S-6 


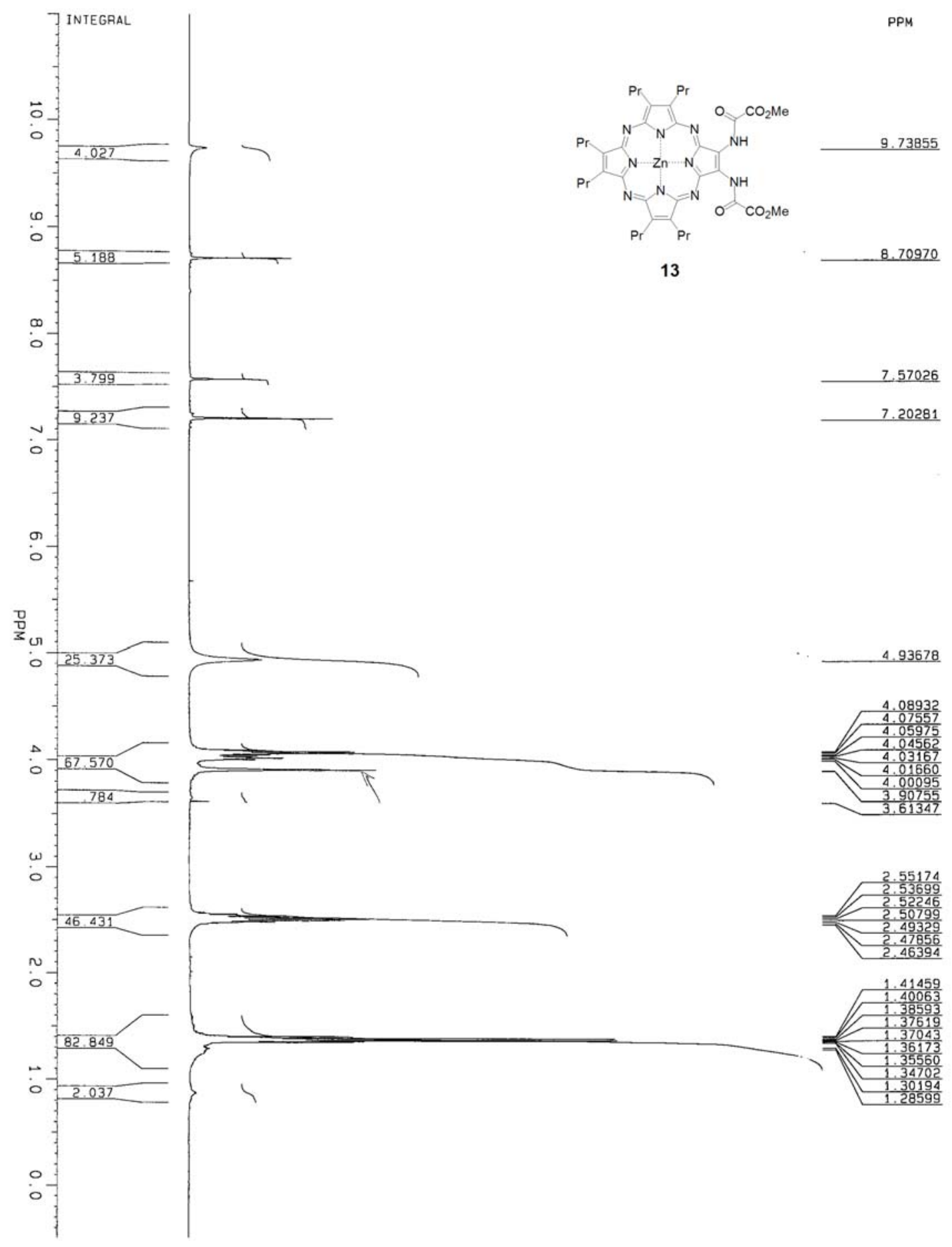




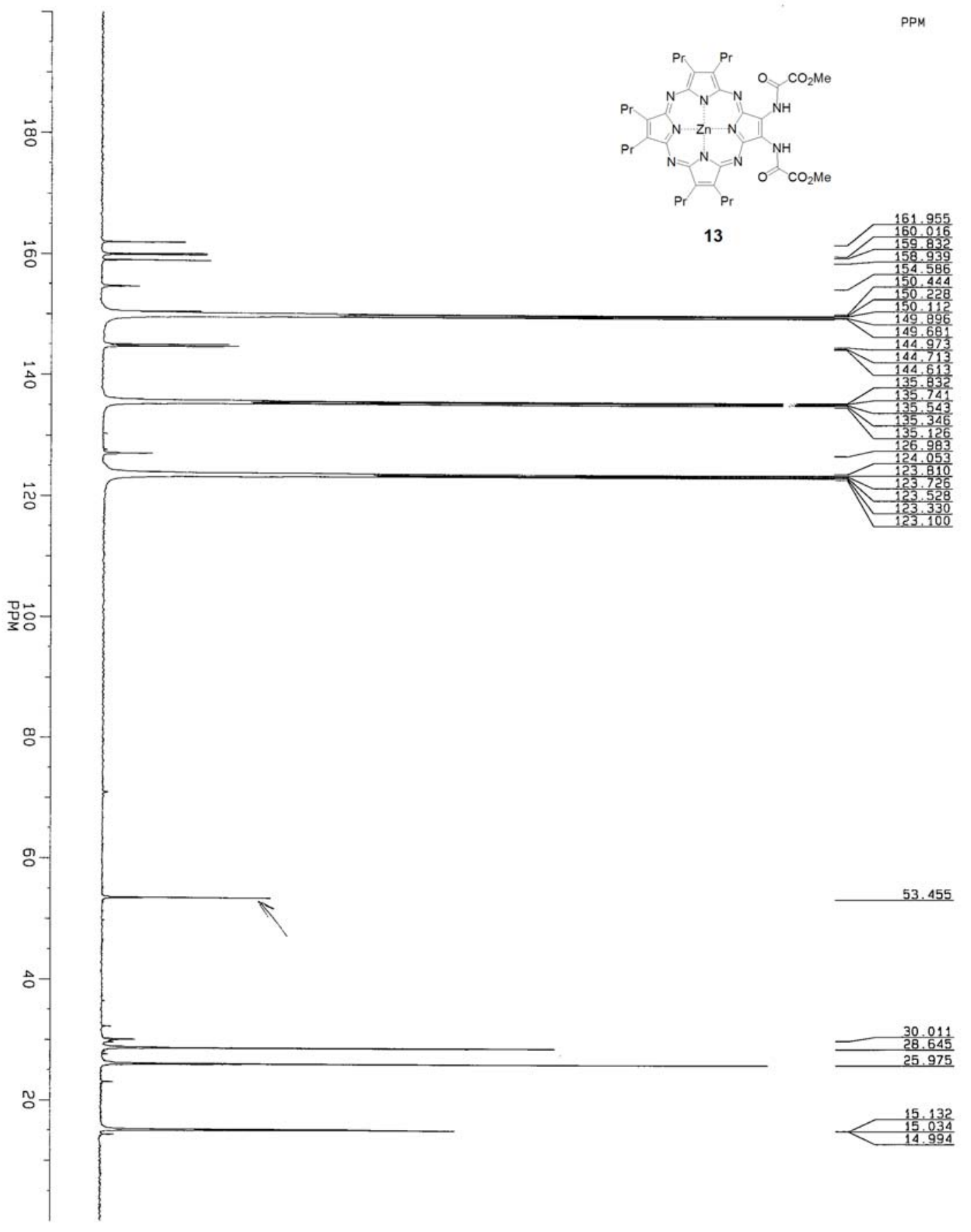




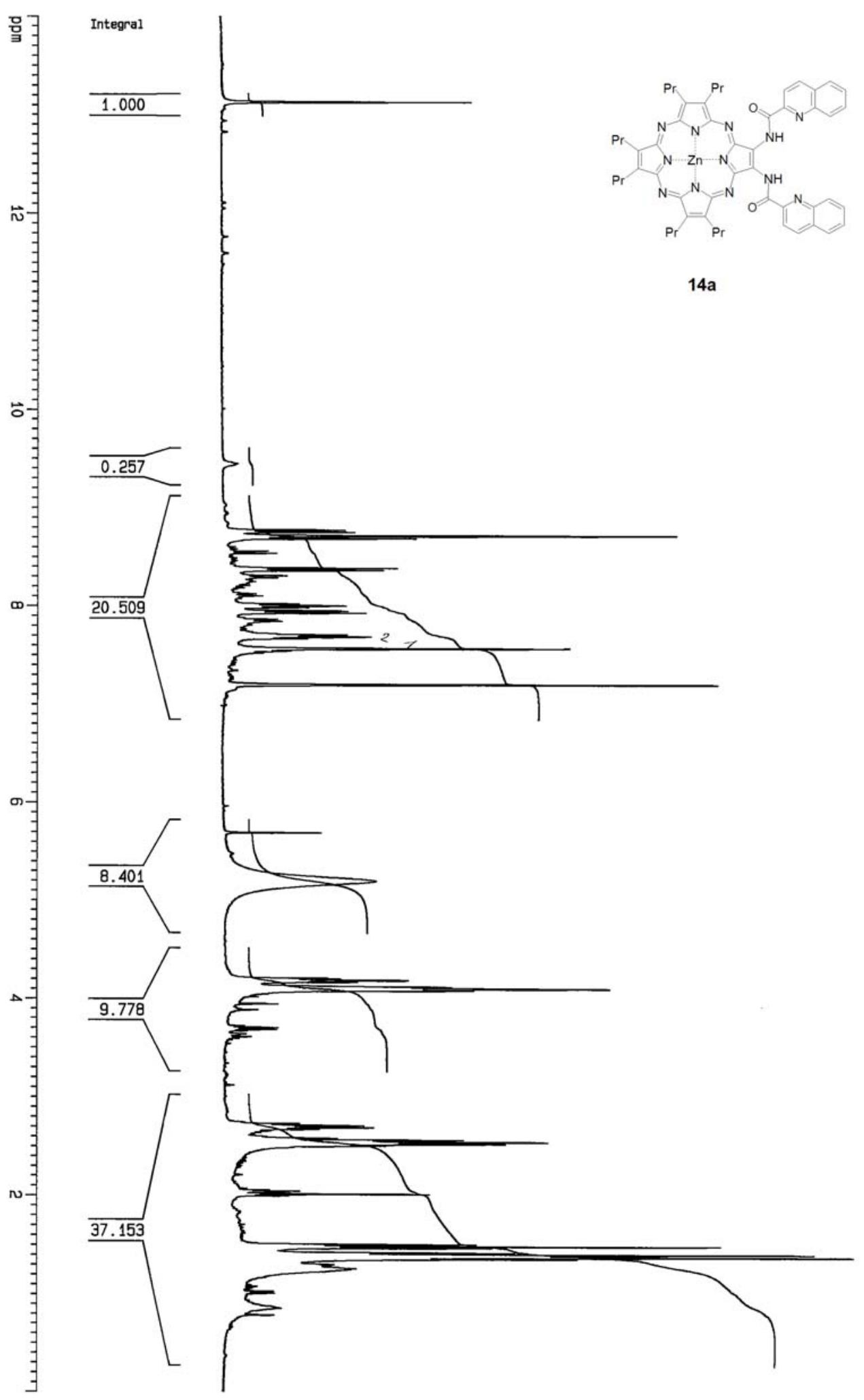




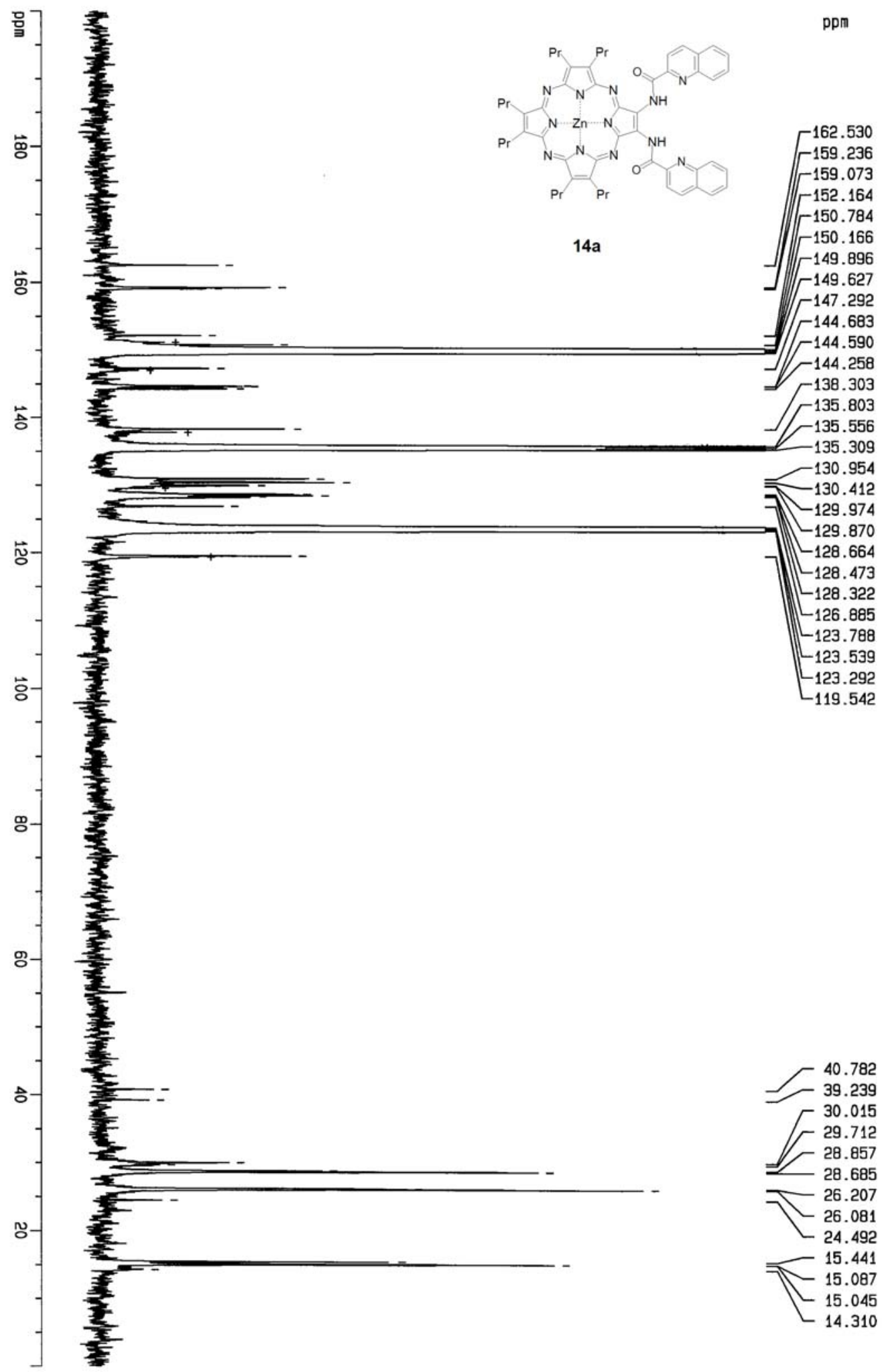




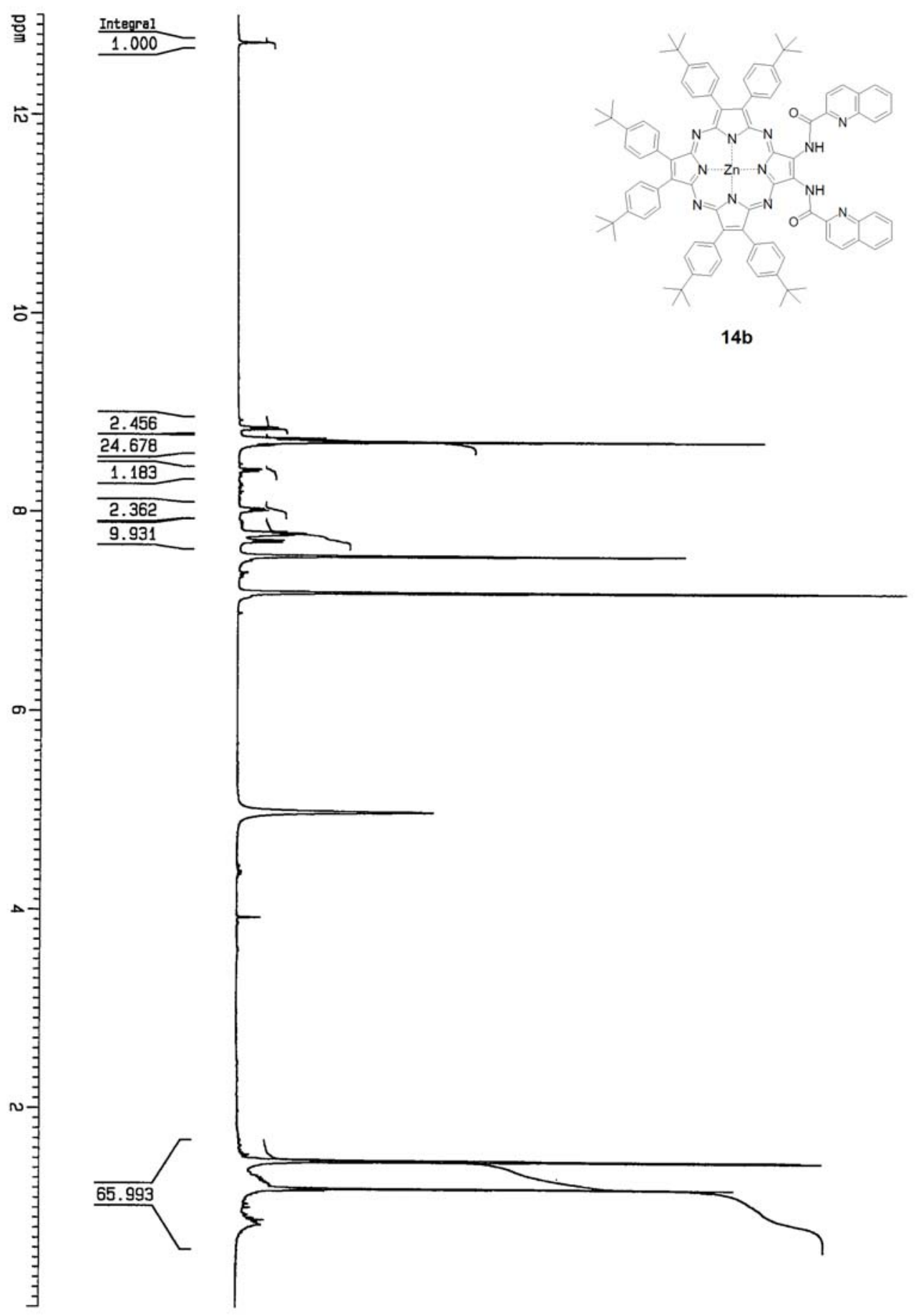




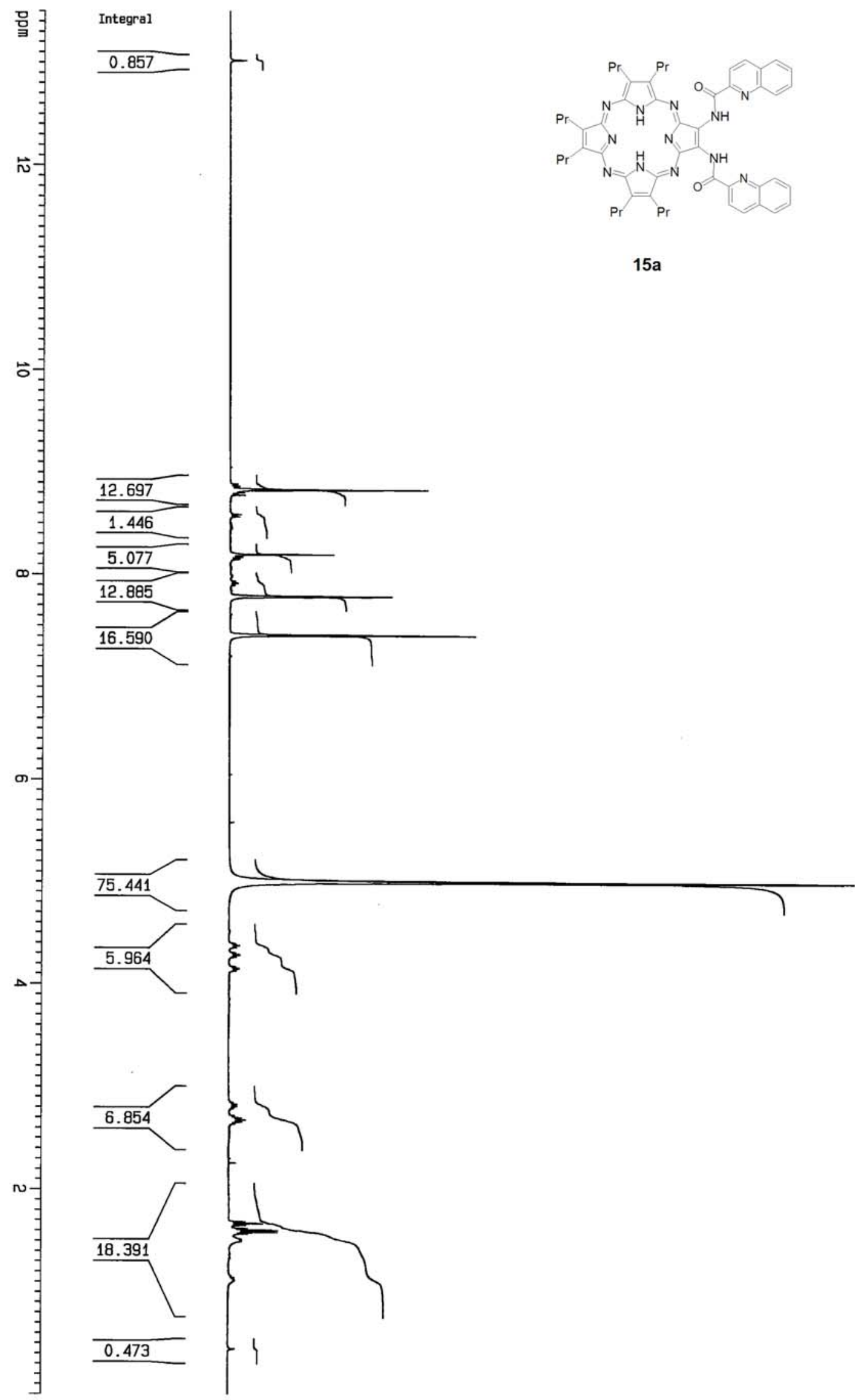




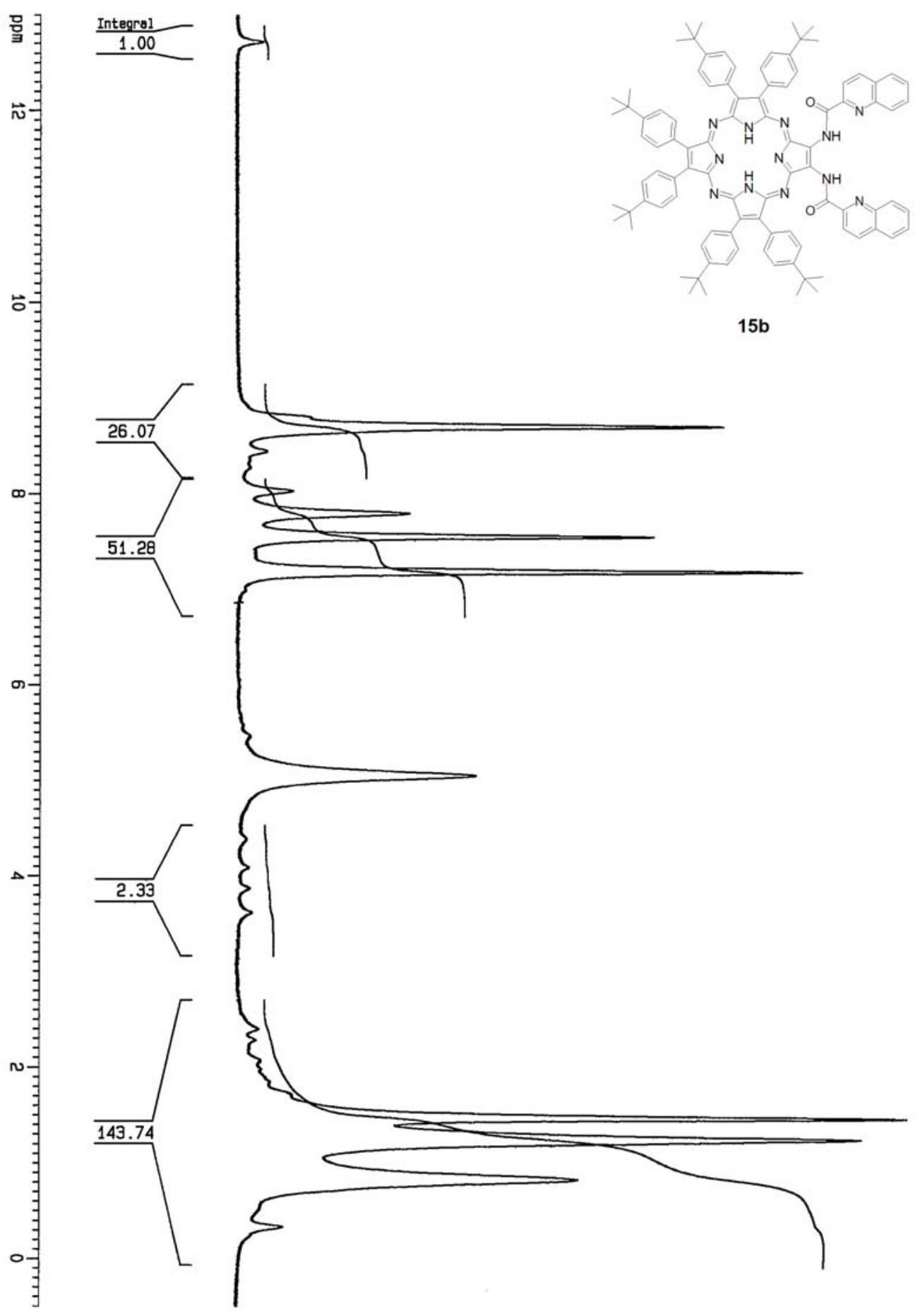




\section{X-ray structure of $14 a$}

The solid state structure of 14a has been determined as both the non-solvated (14a, Fig. S1) and pyridine solvated (14a-2py, see Fig. 2 in the paper) forms (note: both forms have a metal-coordinated pyridine molecule). The less disordered pyridine-solvated version is discussed in the paper. The non-solvated version shows disorder in the $\mathrm{N}(12)$ pyrrole ring, two $50 \%$ occupancy orientations having been identified (see Fig. S2). Both of these orientations give rise to twisted pyrrole rings, so it is no surprise that the adjacent atoms $\mathrm{N}(11)$ and C(14) both show signs of disorder also. Compared to $14 \mathbf{a} \cdot \mathbf{2 p y}$, the porphyrazine ring in $\mathbf{1 4 a}$ is slightly more dished. The zinc lies $c a$. $0.47 \AA$ out of the $\{\mathrm{N}(2), \mathrm{N}(7), \mathrm{N}(12), \mathrm{N}(17)\}$ plane which is coplanar to within $c a .0 .02 \AA$. The outer four nitrogens are coplanar to within $c a .0 .03 \AA$, the inner and outer $\mathrm{N}_{4}$ planes are parallel (inclined by less than $1^{\circ}$ ) and have a mean interplanar separation of $c a .0 .14 \AA$ such that the metal lies $c a .0 .61 \AA$ out of the outer $\{\mathrm{N}(1), \mathrm{N}(6), \mathrm{N}(11), \mathrm{N}(16)\}$ plane. The two quinaldamide moieties have basically the same conformations as seen in $\mathbf{1 4} \cdot \mathbf{a} \mathbf{2} \mathbf{p y}$, again a consequence of the intramolecular $\mathrm{N}-$ $\mathrm{H} \cdots \mathrm{O}$ hydrogen bond between them (a in Fig. S1). For the $\mathrm{N}(21) / \mathrm{N}(24)$ moiety, the amide and quinoline units are inclined by $c a .9^{\circ}$ and the amide is inclined by $c a .23^{\circ}$ to its parent pyrrole ring, whilst for the $\mathrm{N}(33) / \mathrm{N}(36)$ unit the corresponding twists are ca. 7 and $61^{\circ}$. In each case the amide $\mathrm{N}-\mathrm{H}$ is positioned proximal to the quinoline nitrogen, suggesting some $\mathrm{N}-\mathrm{H} \cdots \mathrm{N}$ interaction; the $\mathrm{N}(21)-\mathrm{H} \cdots \mathrm{N}(24)$ and $\mathrm{N}(33)-$ $\mathrm{H} \cdots \mathrm{N}(36) \mathrm{N} \cdots \mathrm{H}$ separations are $c a .2 .16$ and $2.23 \AA$ respectively.

\section{X-ray structure of 3a}

Complex 3a crystallised with two independent molecules (I and II) in the asymmetric unit (see Figs. S8 and S9 respectively), one of which (II) has ca. 57:43 disorder for one side of the porphyrazine ring and its substituents (see Fig. S12).

\section{X-ray structure of $3 b$}

The crystals of complex $\mathbf{3 b}$ contain two independent molecules (I and II) that are actually contain two different chemical compounds, one (I) having an ethanol occupying the apical site on the zinc centre (Fig. S13) whilst the other (II) has an $n$ propanol in this site (Fig. S14). The two complexes are arranged in a back-to-back stack (see Fig. S17) with mean interplanar and centroid $\cdots$ centroid separations for their 
inner $\mathrm{N}_{4}$ atoms of $c a .2 .31$ and $4.91 \AA$ respectively; the $\mathrm{Zn} \cdots \mathrm{Zn}^{\prime}$ and $\mathrm{Se}^{\cdots} \cdot \mathrm{Se}^{\prime}$ separations are 5.404(2) and 4.848(2) Å respectively.

\section{X-ray structure of $14 \mathrm{~b}$}

The crystals of complex $\mathbf{1 4 b}$ contain two different complexes (I and II) superimposed on top of each other. For one of them (I) there is a Zn-pyridine unit "above" the plane of the porphyrazine (Fig. S18), whilst the other (II) has just a zinc centre "below" the plane (Fig. S19). The superimposition of these two complexes can be seen in Fig. S21.

Note that the $\mathrm{N}-\mathrm{H}$ protons [on $\mathrm{N}(21)$ and $\mathrm{N}(33)$ ] could not be located from $\Delta F$ maps and so were placed in optimised positions.

Table S1. Crystallographic Data for compounds 3a, 3b, 8 and $\mathbf{1 4 b}$.

\begin{tabular}{|c|c|c|c|c|}
\hline data & $3 \mathbf{a}$ & $3 \mathbf{b}$ & 8 & $14 b$ \\
\hline & & {$\left[\mathrm{C}_{78} \mathrm{H}_{84} \mathrm{~N}_{10} \mathrm{OSeZn}\right]$} & $\mathrm{C}_{44} \mathrm{H}_{64} \mathrm{~N}_{10} \mathrm{O}_{5} \mathrm{SZn}$ & {$\left[\mathrm{C}_{101} \mathrm{H}_{97} \mathrm{~N}_{13} \mathrm{O}_{2} \mathrm{Zn}\right]_{0 .}$} \\
\hline $\begin{array}{l}\text { chemical } \\
\text { formula }\end{array}$ & $\mathrm{C}_{39} \mathrm{H}_{47} \mathrm{~N}_{11} \mathrm{SeZn}$ & $\begin{array}{c}0.5^{\circ} \\
{\left[\mathrm{C}_{79} \mathrm{H}_{86} \mathrm{~N}_{10} \mathrm{OSeZn}\right]}\end{array}$ & & {$\left[\mathrm{C}_{96} \mathrm{H}_{92} \mathrm{~N}_{12}^{\circ} \mathrm{O}_{2} \mathrm{Zn}\right]_{0.1}$} \\
\hline & & 0.5 & & 5 \\
\hline solvent & - & $1.75 \mathrm{C}_{3} \mathrm{H}_{8} \mathrm{O}$ & $\mathrm{C}_{2} \mathrm{H}_{6} \mathrm{OH}$ & $\begin{array}{c}0.25 \mathrm{C}_{5} \mathrm{H}_{5} \mathrm{~N} \cdot 0.25 \mathrm{C}_{3} \\
\mathrm{H}_{8} \mathrm{O}\end{array}$ \\
\hline fw & 814.21 & 1434.06 & 956.55 & 1613.22 \\
\hline$T\left({ }^{\circ} \mathrm{C}\right)$ & -100 & -100 & -120 & -100 \\
\hline space group & $P \overline{1}$ (no. 2) & $P \overline{1}$ (no. 2) & $P-1$ & $P \overline{1}$ (no. 2$)$ \\
\hline$a(\AA)$ & $10.2170(9)$ & $14.884(2)$ & $115.726(3)$ & $14.4592(19)$ \\
\hline$b(\AA)$ & $15.4684(13)$ & $18.786(3)$ & $95.645(4)$ & $18.004(4)$ \\
\hline$c(\AA)$ & $26.108(2)$ & $29.167(4)$ & $100.672(4)$ & $19.772(2)$ \\
\hline$\alpha(\operatorname{deg})$ & $82.207(7)$ & $80.101(12)$ & $11.170(3)$ & $97.654(16)$ \\
\hline$\beta(\operatorname{deg})$ & $83.440(7)$ & $82.475(13)$ & $16.138(4)$ & $100.365(10)$ \\
\hline$\gamma(\mathrm{deg})$ & $70.071(8)$ & $86.301(12)$ & $16.255(4)$ & $112.803(14)$ \\
\hline$V\left(\AA^{3}\right)$ & $3833.0(6)$ & $7957(2)$ & $2540.7(10)$ & $4549.1(12)$ \\
\hline$Z$ & $4[\mathrm{a}]$ & 4 [a] & 2 & 2 \\
\hline$\rho_{\text {calcd }}\left(\mathrm{g} \mathrm{cm}^{-3}\right)$ & 1.411 & 1.197 & 1.250 & 1.178 \\
\hline$\lambda(\AA)$ & 0.71073 & 1.54248 & 0.71073 & 1.54248 \\
\hline$\mu\left(\mathrm{mm}^{-1}\right)$ & 1.635 & 1.355 & 0.579 & 0.813 \\
\hline$R_{1}[\mathrm{~b}]$ & 0.076 & 0.138 & 0.1145 & 0.149 \\
\hline$w R_{2}[\mathrm{c}]$ & 0.167 & 0.332 & 0.2412 & 0.343 \\
\hline
\end{tabular}

[a] There are two crystallographically independent molecules in the asymmetric unit. [b] $R_{1}=\Sigma|| F_{\mathrm{o}}|-| F_{\mathrm{c}}|| \Sigma\left|F_{\mathrm{o}}\right|$. $[\mathrm{c}] w R_{2}=\left\{\Sigma\left[w\left(F_{\mathrm{o}}^{2}-F_{\mathrm{c}}^{2}\right)^{2}\right] / \Sigma\left[w\left(F_{\mathrm{o}}^{2}\right)^{2}\right]\right\}^{1 / 2} ; w^{-1}=\sigma^{2}\left(F_{\mathrm{o}}^{2}\right)+(a P)^{2}+b P$.

Table S1 provides a summary of the crystallographic data for compounds $\mathbf{3 a}, \mathbf{3 b}, \mathbf{8}$ and 14b. CCDC 294756 (3a), 294757 (3b), 297170 (8), 294760 (14b). 
Table S2. Crystallographic Data for compounds 14a, 14a·2py, 18a and 20.

\begin{tabular}{lcccc}
\hline \multicolumn{1}{c}{ data } & $\mathbf{1 4 a}$ & $\mathbf{1 4 a \cdot 2} \mathbf{p y}$ & $\mathbf{1 8 a}$ & $\mathbf{2 0}$ \\
\hline chemical formula & $\mathrm{C}_{59} \mathrm{H}_{61} \mathrm{~N}_{13} \mathrm{O}_{2} \mathrm{Zn}$ & $\mathrm{C}_{59} \mathrm{H}_{61} \mathrm{~N}_{13} \mathrm{O}_{2} \mathrm{Zn}$ & $\mathrm{C}_{112} \mathrm{H}_{120} \mathrm{Cu}_{2} \mathrm{~N}_{24} \mathrm{O}_{6} \mathrm{Zn}_{2}$ & $\mathrm{C}_{51} \mathrm{H}_{59} \mathrm{ClCuFeN}_{11} \mathrm{O}_{2}$ \\
solvent & - & $2 \mathrm{C}_{5} \mathrm{H}_{5} \mathrm{~N}$ & $4 \mathrm{EtOH}$ & - \\
$\mathrm{fw}$ & 1049.58 & 1207.78 & 2340.41 & 1012.93 \\
$T\left({ }^{\circ} \mathrm{C}\right)$ & -100 & -100 & -100 & -100 \\
space group & $P \overline{1}(\mathrm{no.} 2)$ & $P \overline{1}($ no. 2$)$ & $P \overline{4} 2{ }_{1} c($ no. 114) & $P \overline{1}(\mathrm{no.} 2)$ \\
$a(\AA)$ & $12.7189(6)$ & $12.1703(5)$ & $17.2570(17)$ & $10.7996(15)$ \\
$b(\AA)$ & $15.0091(7)$ & $15.7922(7)$ & - & $15.203(3)$ \\
$c(\AA)$ & $16.2443(6)$ & $17.5468(7)$ & $39.409(4)$ & $16.414(2)$ \\
$\alpha(\mathrm{deg})$ & $108.615(4)$ & $90.108(3)$ & - & $91.961(18)$ \\
$\beta(\mathrm{deg})$ & $96.780(4)$ & $90.338(3)$ & - & $108.348(12)$ \\
$\gamma(\mathrm{deg})$ & $110.697(4)$ & $111.202(4)$ & - & $106.412(14)$ \\
$V\left(\AA^{3}\right)$ & $2654.3(2)$ & $3144.1(2)$ & $11736(2)$ & $2431.1(6)$ \\
$Z$ & 2 & 2 & $4[\mathrm{a}]$ & 2 \\
$\rho_{\text {calcd }}\left(\mathrm{g} \mathrm{cm}{ }^{-3}\right)$ & 1.313 & 1.276 & 1.325 & 1.384 \\
$\lambda(\AA)$ & 0.71073 & 0.71073 & 1.54248 & 1.54248 \\
$\mu\left(\mathrm{mm}^{-1}\right)$ & 0.520 & 0.449 & 1.418 & 3.854 \\
$R_{1}[\mathrm{~b}]$ & 0.075 & 0.082 & 0.167 & 0.071 \\
$w R_{2}[\mathrm{c}]$ & 0.172 & 0.191 & 0.449 & 0.184
\end{tabular}

[a] The molecule has crystallographic $C_{2}$ symmetry. [b] $R_{1}=\Sigma|| F_{\mathrm{o}}|-| F_{\mathrm{c}}|| \Sigma\left|F_{\mathrm{o}}\right| \cdot[\mathrm{c}] w R_{2}=\left\{\Sigma\left[w\left(F_{\mathrm{o}}{ }^{2}-F_{\mathrm{c}}{ }^{2}\right)^{2}\right] /\right.$ $\left.\Sigma\left[w\left(F_{\mathrm{o}}{ }^{2}\right)^{2}\right]\right\}^{1 / 2} ; w^{-1}=\sigma^{2}\left(F_{\mathrm{o}}{ }^{2}\right)+(a P)^{2}+b P$.

Table S2 provides a summary of the crystallographic data for compounds 14a, $14 a \cdot 2 p y, 18 a$ and 20 . The absolute structure of 18 a could not be unambiguously determined by either an $R$-factor test $\left[R_{1}{ }^{+}=0.1671, R_{1}^{-}=0.1678\right]$ or by use of the Flack parameter $\left[x^{+}=+0.27(8), x^{-}=+0.73(8)\right]$. CCDC 294758 (14a), 294759 (14a·2py), 294761 (18a) and 294762 (20).

Table S3. Selected bond lengths $(\AA)$ and angles $\left(^{\circ}\right)$ for $\mathbf{1 4 a}$.

$\begin{array}{lclc}\mathrm{Zn}-\mathrm{N}(2) & 2.0195(17) & \mathrm{Zn}-\mathrm{N}(7) & 2.0137(18) \\ \mathrm{Zn}-\mathrm{N}(12) & 2.0112(18) & \mathrm{Zn}-\mathrm{N}(17) & 2.0184(17) \\ \mathrm{Zn}-\mathrm{N}(63) & 2.1273(19) & & \\ \mathrm{N}(2)-\mathrm{Zn}-\mathrm{N}(7) & 85.22(7) & \mathrm{N}(2)-\mathrm{Zn}-\mathrm{N}(12) & 152.16(8) \\ \mathrm{N}(2)-\mathrm{Zn}-\mathrm{N}(17) & 87.42(7) & \mathrm{N}(2)-\mathrm{Zn}-\mathrm{N}(63) & 104.02(7) \\ \mathrm{N}(7)-\mathrm{Zn}-\mathrm{N}(12) & 88.03(8) & \mathrm{N}(7)-\mathrm{Zn}-\mathrm{N}(17) & 153.88(8) \\ \mathrm{N}(7)-\mathrm{Zn}-\mathrm{N}(63) & 103.85(8) & \mathrm{N}(12)-\mathrm{Zn}-\mathrm{N}(17) & 86.87(7) \\ \mathrm{N}(12)-\mathrm{Zn}-\mathrm{N}(63) & 103.82(8) & \mathrm{N}(17)-\mathrm{Zn}-\mathrm{N}(63) & 102.24(7)\end{array}$


Table S4. Selected bond lengths $(\AA)$ and angles $\left(^{\circ}\right)$ for the two independent molecules (I and II) present in the crystals of $\mathbf{3 a}$.

Mol I Mol II

$\begin{array}{lcclcc}\mathrm{Zn}-\mathrm{N}(2) & 2.053(3) & 2.053(3) & \mathrm{Zn}-\mathrm{N}(7) & 1.991(3) & 2.009(4) \\ \mathrm{Zn}-\mathrm{N}(12) & 2.012(3) & 2.072(6) & \mathrm{Zn}-\mathrm{N}(17) & 2.012(2) & 2.016(3) \\ \mathrm{Zn}-\mathrm{N}(41) & 2.139(3) & 2.132(3) & \mathrm{Se}-\mathrm{N}(21) & 1.820(3) & 1.830(3) \\ \mathrm{Se}-\mathrm{N}(22) & 1.813(3) & 1.828(3) & & & \\ \mathrm{N}(2)-\mathrm{Zn}-\mathrm{N}(7) & 86.54(10) & 86.84(11) & \mathrm{N}(2)-\mathrm{Zn}-\mathrm{N}(12) & 155.39(11) & 151.4(4) \\ \mathrm{N}(2)-\mathrm{Zn}-\mathrm{N}(17) & 87.74(10) & 86.89(12) & \mathrm{N}(2)-\mathrm{Zn}-\mathrm{N}(41) & 101.80(11) & 100.50(12) \\ \mathrm{N}(7)-\mathrm{Zn}-\mathrm{N}(12) & 88.56(11) & 84.8(2) & \mathrm{N}(7)-\mathrm{Zn}-\mathrm{N}(17) & 154.94(11) & 153.26(14) \\ \mathrm{N}(7)-\mathrm{Zn}-\mathrm{N}(41) & 106.45(11) & 109.03(15) & \mathrm{N}(12)-\mathrm{Zn}-\mathrm{N}(17) & 86.56(11) & 88.41(19) \\ \mathrm{N}(12)-\mathrm{Zn}- & 102.72(11) & 108.1(4) & \mathrm{N}(17)-\mathrm{Zn}-\mathrm{N}(41) & 98.60(10) & 97.67(14) \\ \mathrm{N}(21)-\mathrm{Se}- & 93.93(12) & 93.50(13) & & & \end{array}$

Table S5. Selected bond lengths $(\AA)$ and angles $\left(^{\circ}\right)$ for the ethanol and $n$-propanol coordinated complexes (I and II) present in the crystals of $\mathbf{3 b}$.

$\begin{array}{cclcc}\text { Mol I } & \text { Mol II } & & \text { Mol I } & \text { Mol II } \\ 2.013(8) & 2.033(8) & \mathrm{Zn}-\mathrm{N}(7) & 2.003(8) & 1.996(8) \\ 1.986(8) & 1.985(8) & \mathrm{Zn}-\mathrm{N}(17) & 2.018(8) & 2.030(8) \\ 2.142(9) & 2.117(9) & \mathrm{Se}-\mathrm{N}(21) & 1.829(9) & 1.823(9) \\ 1.846(8) & 1.821(8) & & & \\ & & & & \\ 89.5(3) & 87.9(3) & \mathrm{N}(2)-\mathrm{Zn}-\mathrm{N}(12) & 161.9(4) & 160.0(4) \\ 86.9(3) & 87.4(3) & \mathrm{N}(2)-\mathrm{Zn}-\mathrm{O}(90) & 101.8(4) & 95.9(4) \\ 88.4(3) & 88.5(3) & \mathrm{N}(7)-\mathrm{Zn}-\mathrm{N}(17) & 159.9(4) & 158.7(4) \\ 98.9(4) & 99.6(4) & \mathrm{N}(12)-\mathrm{Zn}-\mathrm{N}(17) & 88.9(3) & 88.8(3) \\ 96.3(4) & 104.1(4) & \mathrm{N}(17)-\mathrm{Zn}-\mathrm{O}(90) & 101.2(4) & 101.5(4) \\ 94.6(3) & 94.0(4) & & & \end{array}$

Table S6. Selected bond lengths $(\AA)$ and angles $\left(^{\circ}\right)$ for the pyridine-coordinated (I) and non-pyridine-coordinated (II) complexes present in the crystals of $14 b$.

$\begin{array}{lcclcc} & \text { Mol I } & \text { Mol II } & & \text { Mol I } & \text { Mol II } \\ \text { Zn-N(2) } & 2.029(6) & 2.040(11) & \mathrm{Zn}-\mathrm{N}(7) & 2.032(6) & 2.059(11) \\ \mathrm{Zn}-\mathrm{N}(12) & 2.011(6) & 1.977(11) & \mathrm{Zn}-\mathrm{N}(17) & 2.040(6) & 2.027(11) \\ \mathrm{Zn}-\mathrm{N}(105) & 2.077(10) & \mathrm{n} / \mathrm{a} & & & \\ \mathrm{N}(2)-Z n-\mathrm{N}(7) & 85.8(2) & 84.7(4) & \mathrm{N}(2)-\mathrm{Zn}-\mathrm{N}(12) & 150.1(3) & 152.5(7) \\ \mathrm{N}(2)-\mathrm{Zn}-\mathrm{N}(17) & 86.1(2) & 86.2(4) & \mathrm{N}(2)-\mathrm{Zn}-\mathrm{N}(105) & 104.0(3) & \mathrm{n} / \mathrm{a} \\ \mathrm{N}(7)-Z n-\mathrm{N}(12) & 87.8(2) & 87.9(5) & \mathrm{N}(7)-\mathrm{Zn}-\mathrm{N}(17) & 152.4(3) & 150.8(7) \\ \mathrm{N}(7)-Z n-\mathrm{N}(105) & 109.6(3) & \mathrm{n} / \mathrm{a} & \mathrm{N}(12)-\mathrm{Zn}-\mathrm{N}(17) & 86.3(2) & 87.5(4) \\ \mathrm{N}(12)-\mathrm{Zn}-\mathrm{N}(105) & 105.6(3) & \mathrm{n} / \mathrm{a} & \mathrm{N}(17)-\mathrm{Zn}-\mathrm{N}(105) & 97.9(3) & \mathrm{n} / \mathrm{a}\end{array}$




\section{Figures}

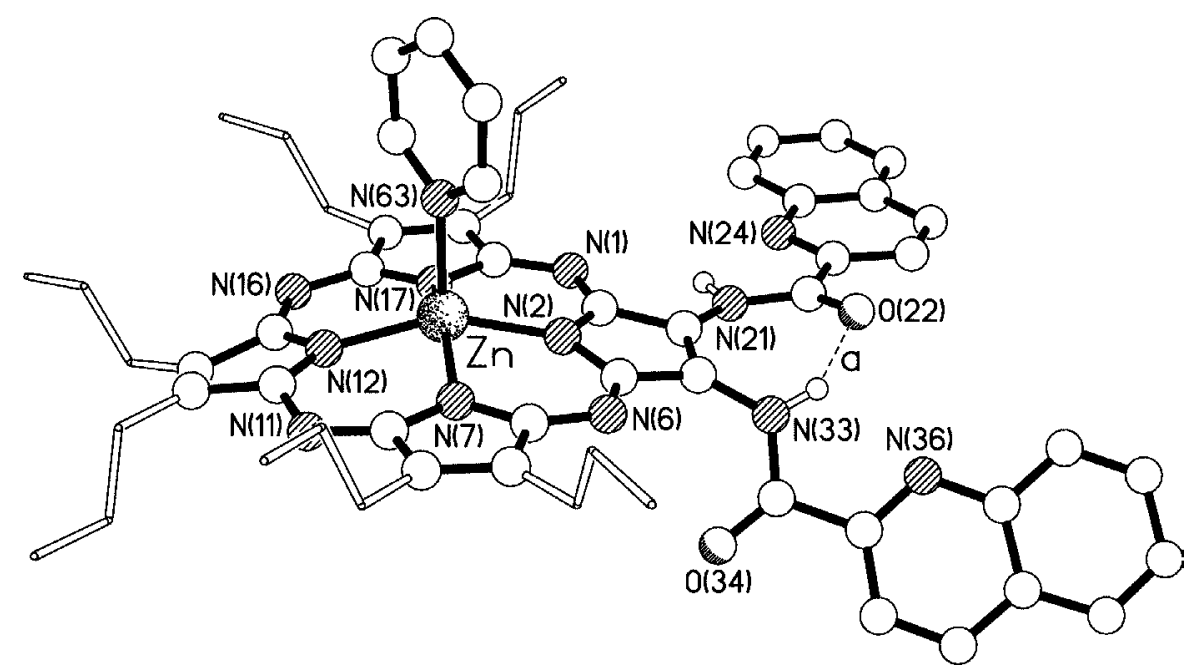

Fig. S1 The molecular structure of 14a showing the major (50\% occupancy) orientation for the disorder in $\mathrm{N}(12)$ pyrrole ring. The $\mathrm{N}-\mathrm{H} \cdots \mathrm{O}$ hydrogen bond (a) has $\mathrm{N} \cdots \mathrm{O} 2.805(2) \AA, \mathrm{H} \cdots \mathrm{O} 2.05 \AA$ and $\mathrm{N}-\mathrm{H} \cdots \mathrm{O} 140^{\circ}$.

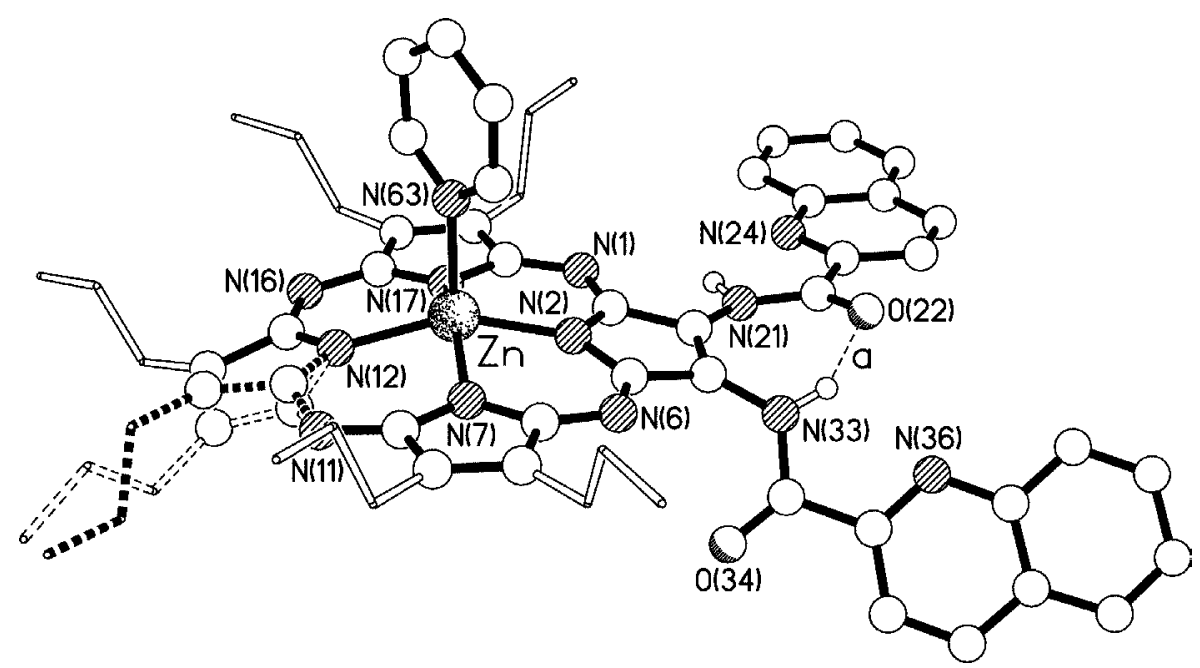

Fig. S2 The molecular structure of 14a showing both orientations for the disorder in $\mathrm{N}(12)$ pyrrole ring; both orientations are 50\% occupancy. 


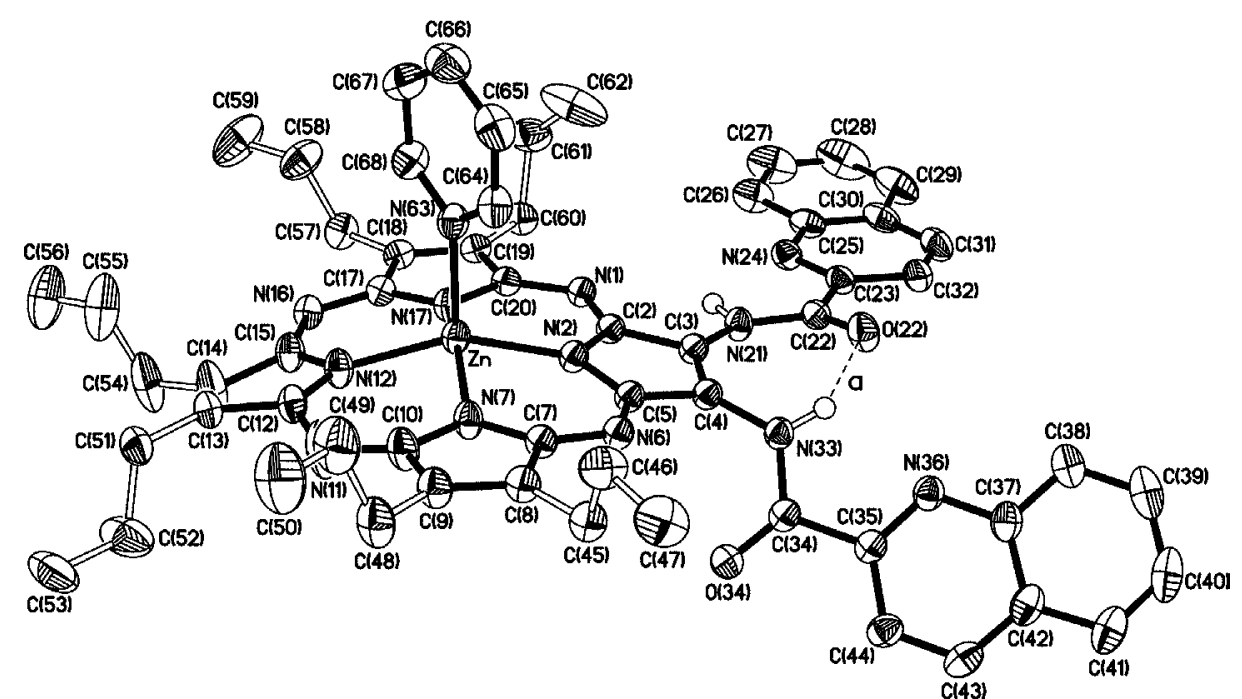

Fig. S3 The molecular structure of $\mathbf{1 4 a}$ (50\% probability ellipsoids).

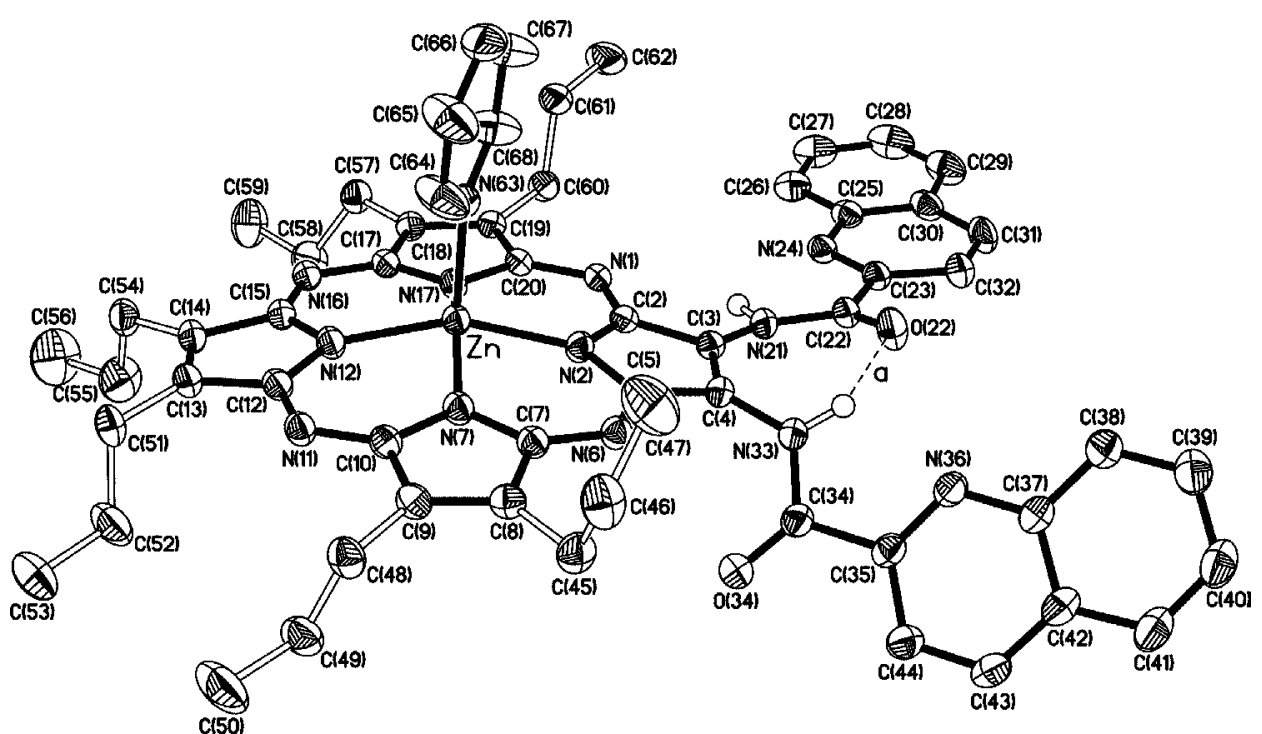

Fig. S4 The molecular structure of $\mathbf{1 4 a \cdot 2} \mathbf{p y}(50 \%$ probability ellipsoids).

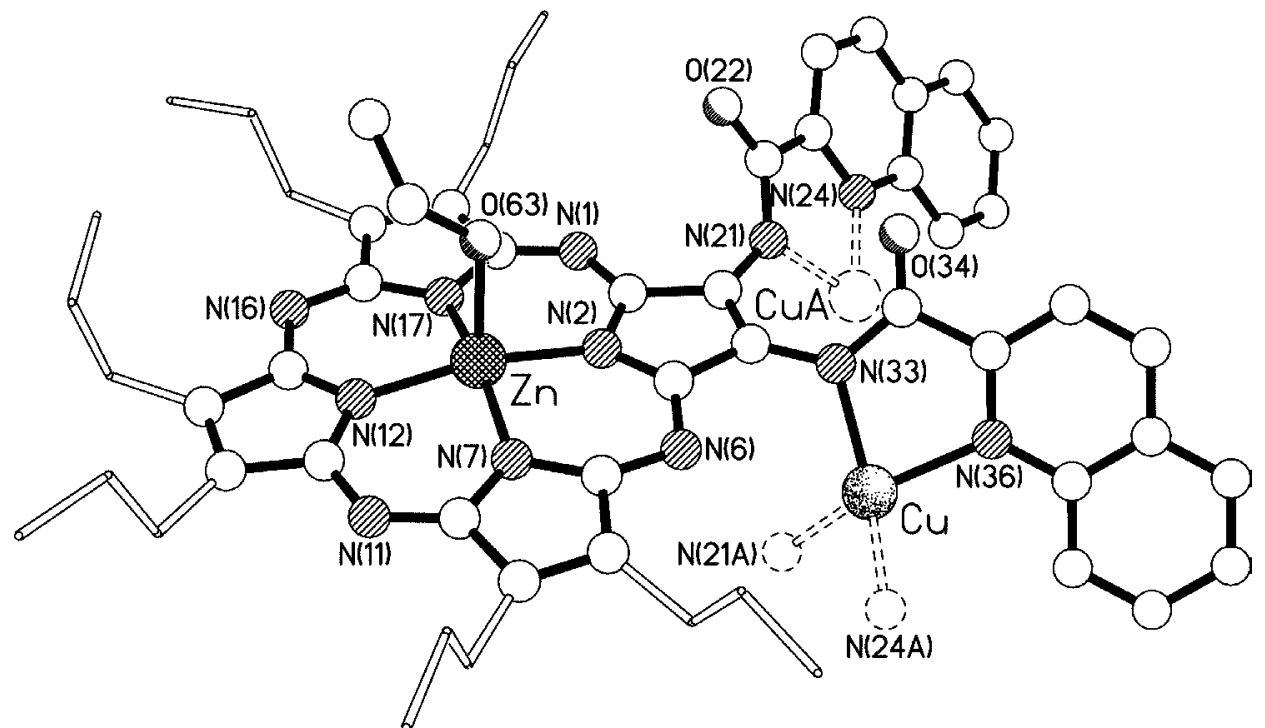

Fig. S5 The molecular structure of the unique portion of the $C_{2}$-symmetric complex 18a. 


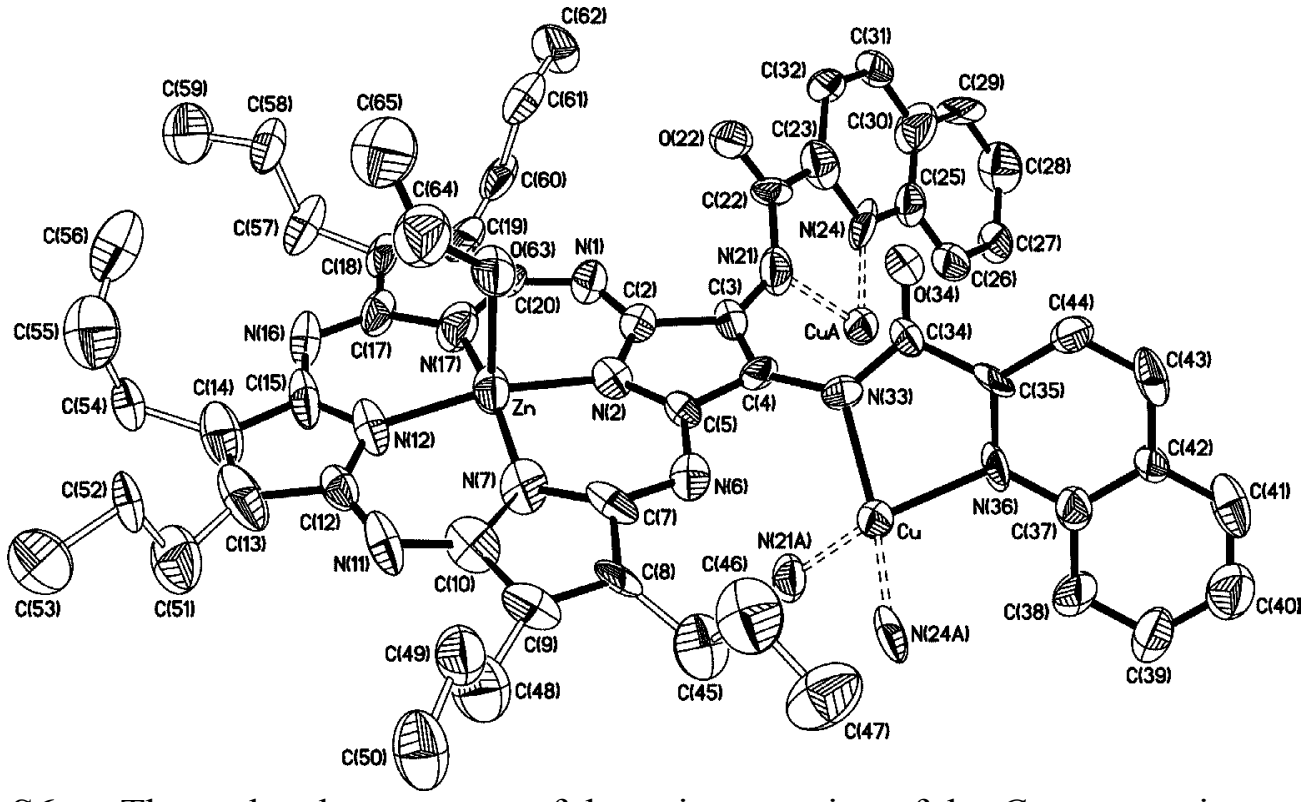

Fig. S6 The molecular structure of the unique portion of the $C_{2}$-symmetric complex $\mathbf{1 8 a}$ ( $20 \%$ probability ellipsoids).

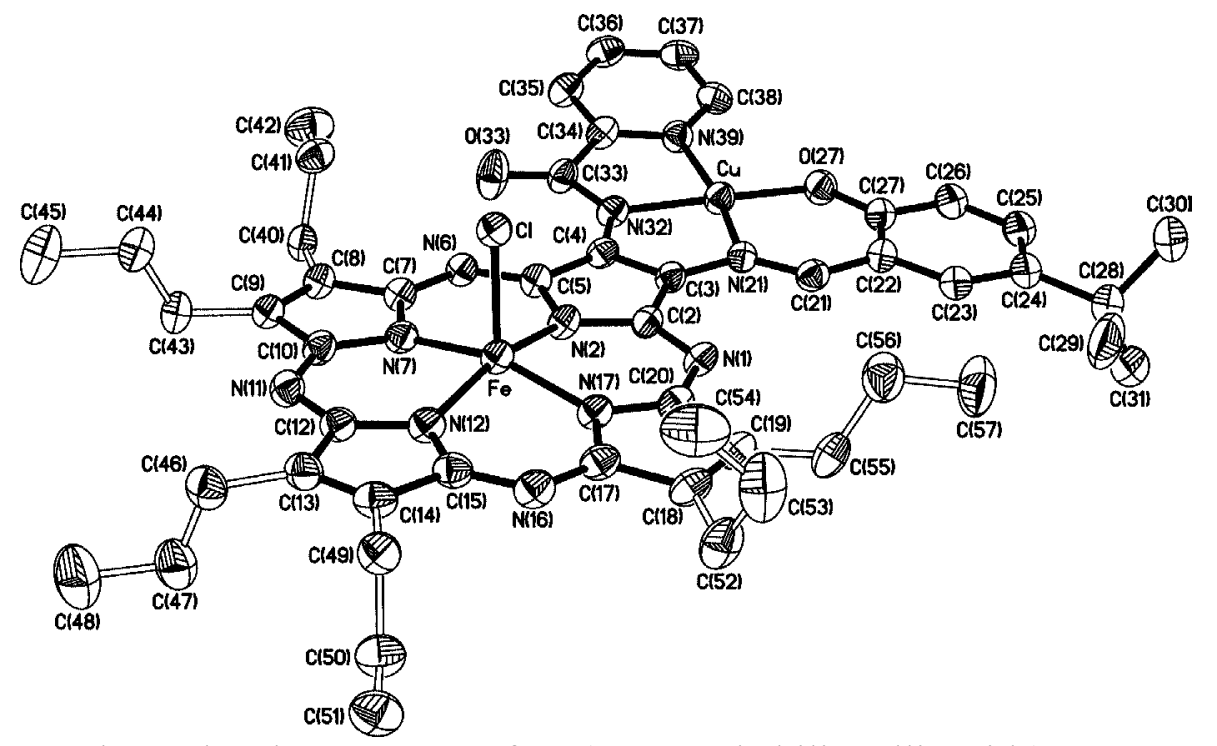

Fig. S7 The molecular structure of $\mathbf{2 0}$ (30\% probability ellipsoids). 


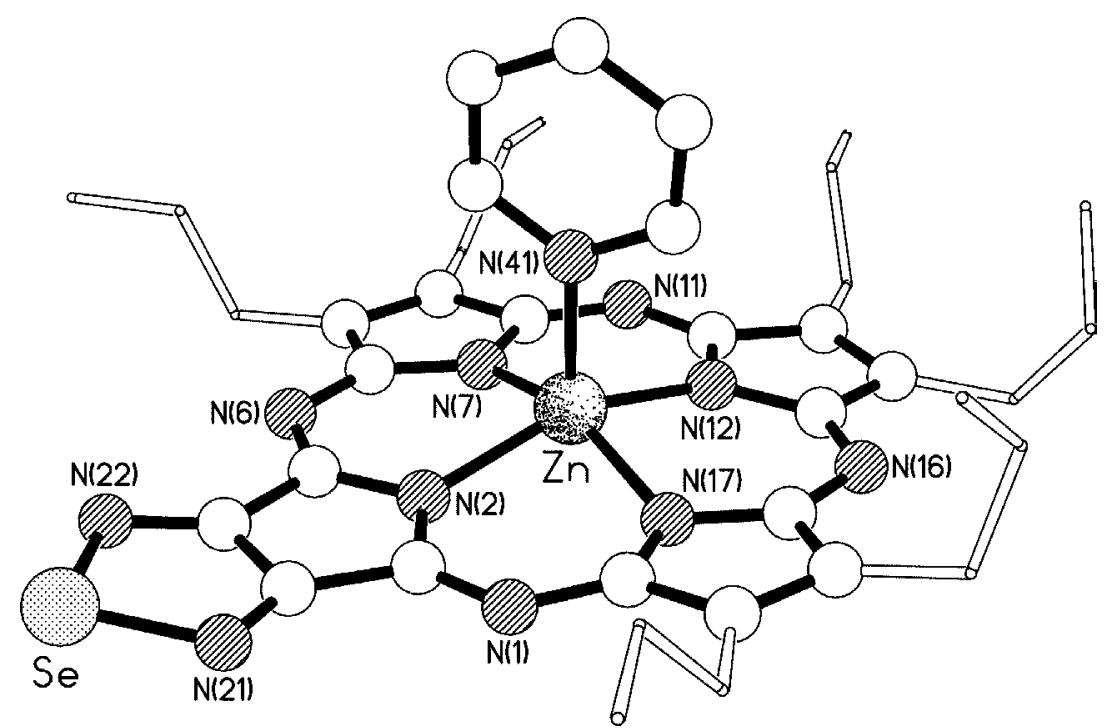

Fig. S8 The molecular structure of one (I) of the two independent molecules present in the crystals of $\mathbf{3 a}$.

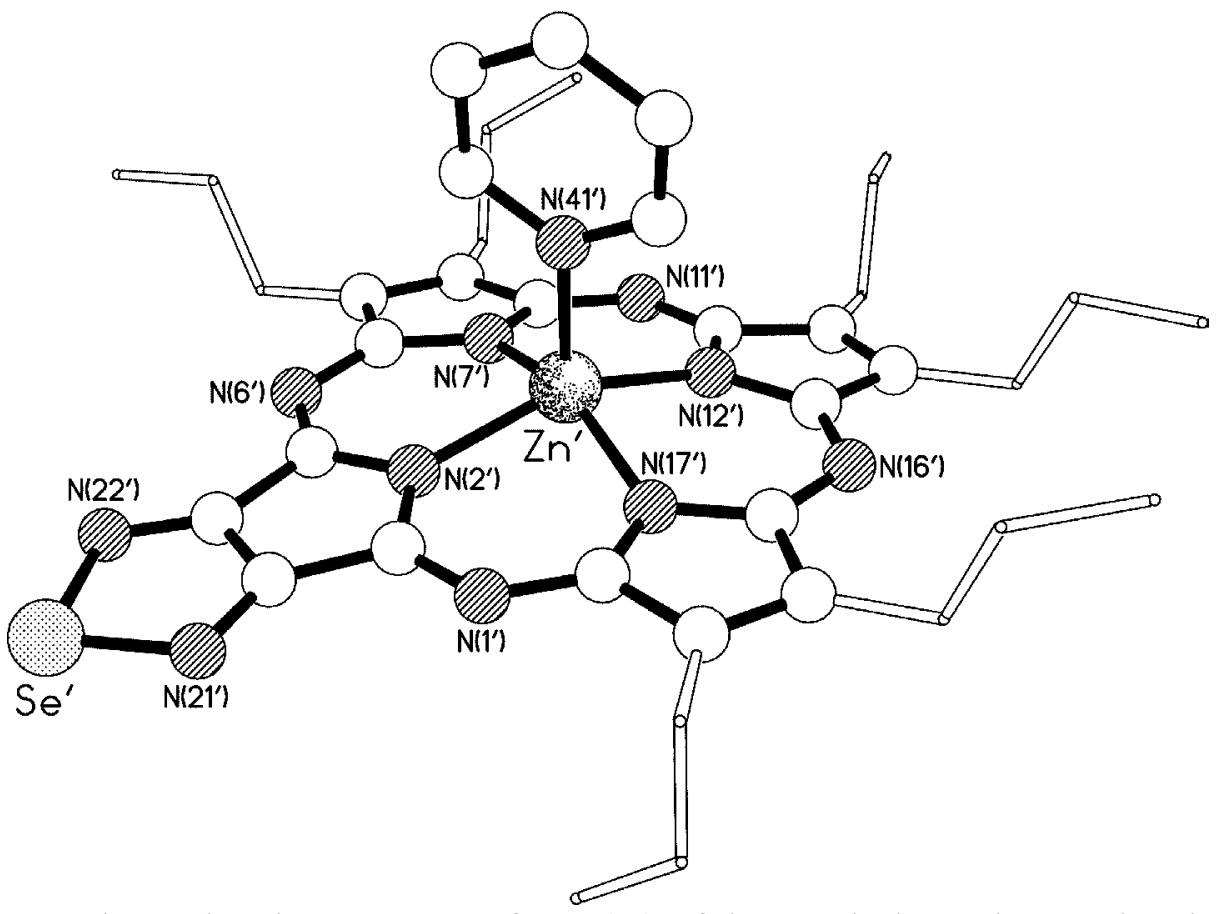

Fig. S9 The molecular structure of one (II) of the two independent molecules present in the crystals of $\mathbf{3 a}$. 


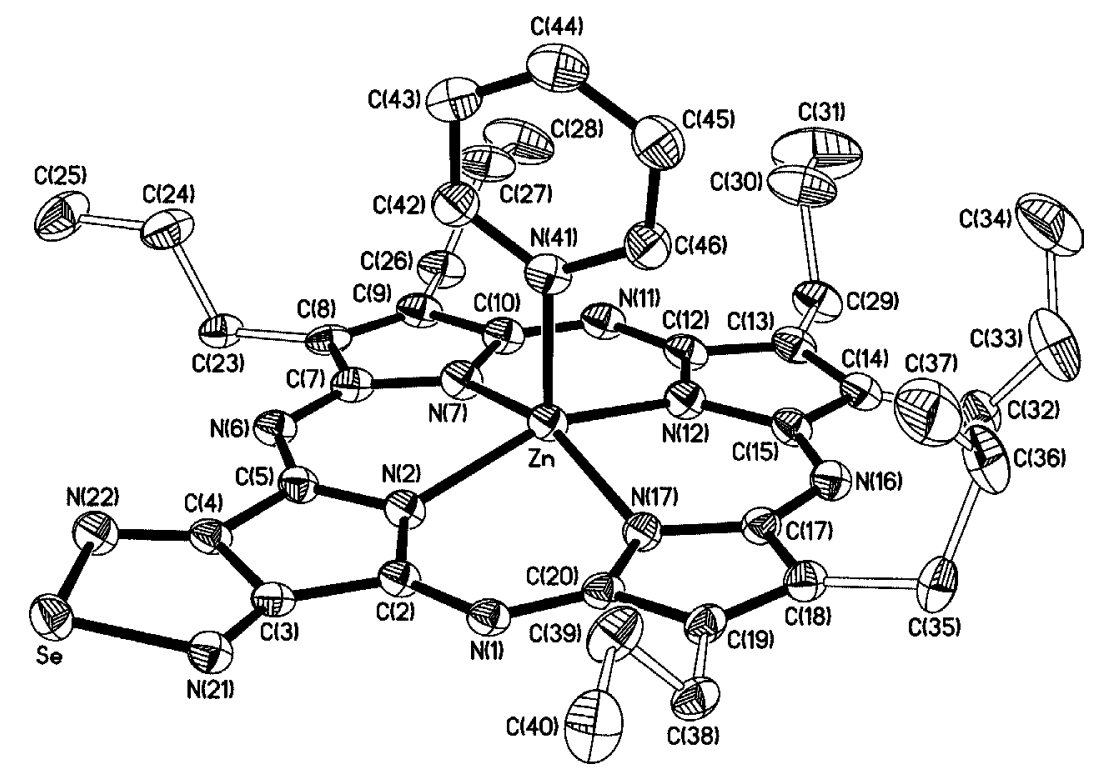

Fig. S10 The molecular structure of one (I) of the two independent molecules present in the crystals of $\mathbf{3 a}$ (50\% probability ellipsoids).

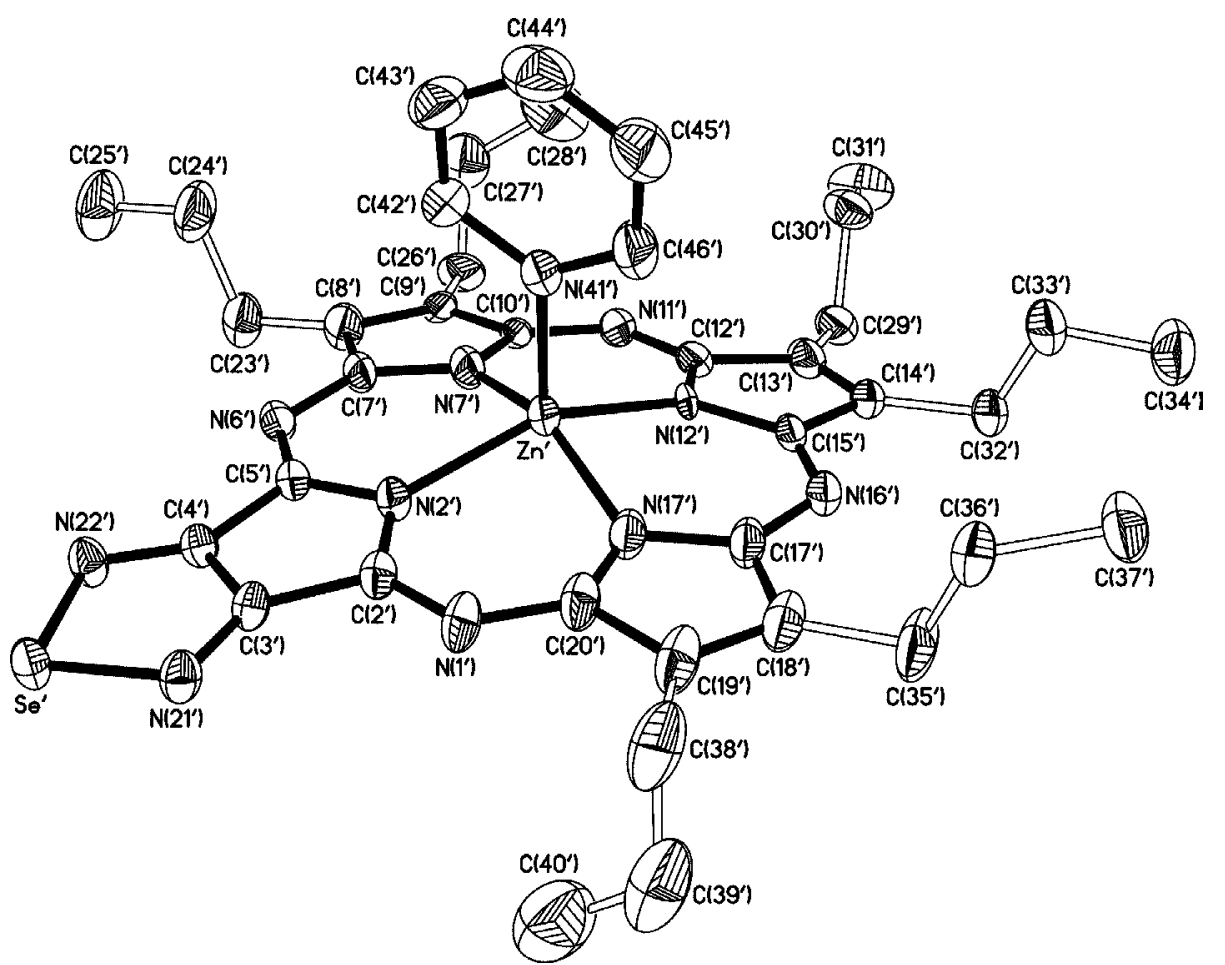

Fig. S11 The molecular structure of one (II) of the two independent molecules present in the crystals of $\mathbf{3 a}$ (50\% probability ellipsoids). 


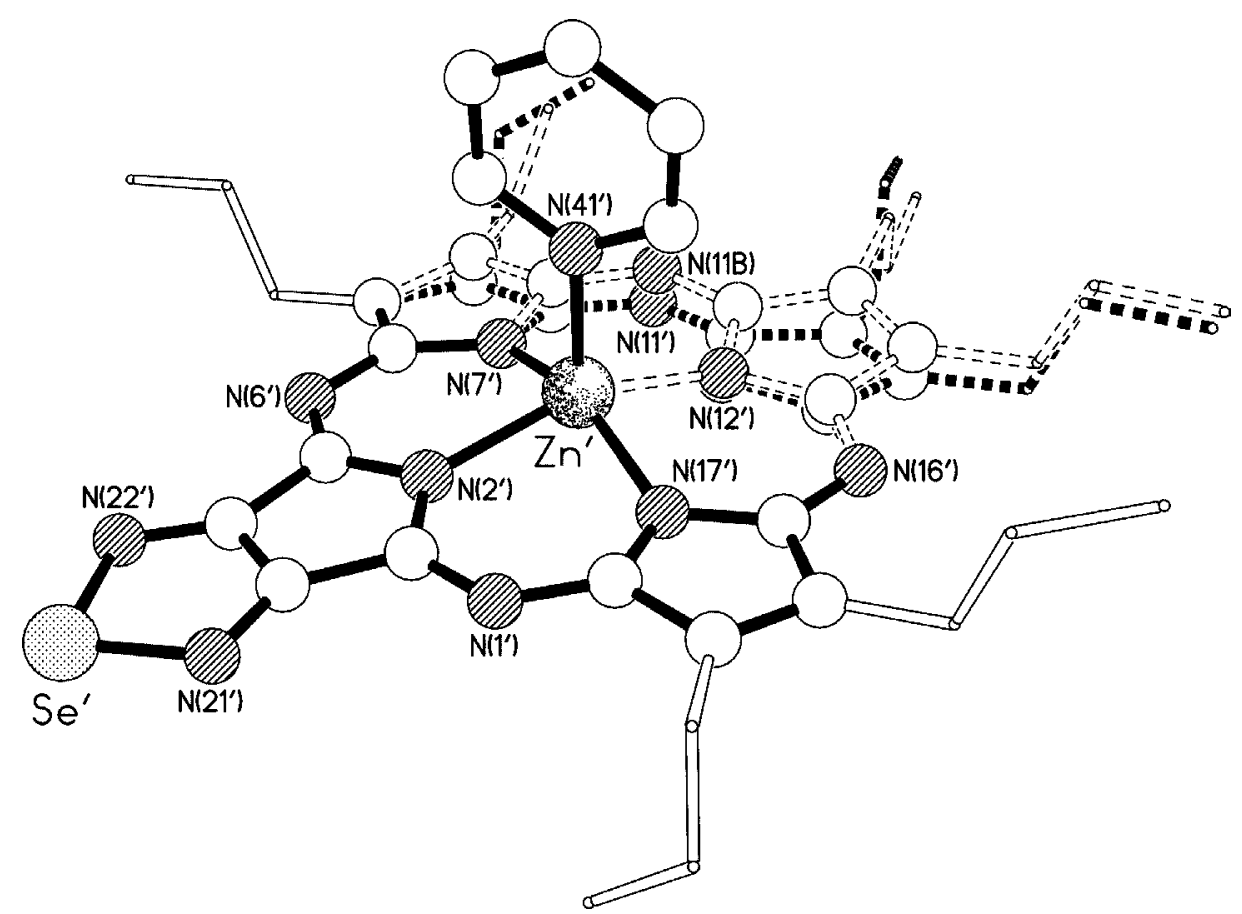

Fig. S12 The molecular structure of one (II) of the two independent molecules present in the crystals of 3a showing the $c a$. 57:43 disorder in the porphyrazine ring (the major occupancy orientation is drawn with filled dashed bonds, the minor with open dashed bonds).

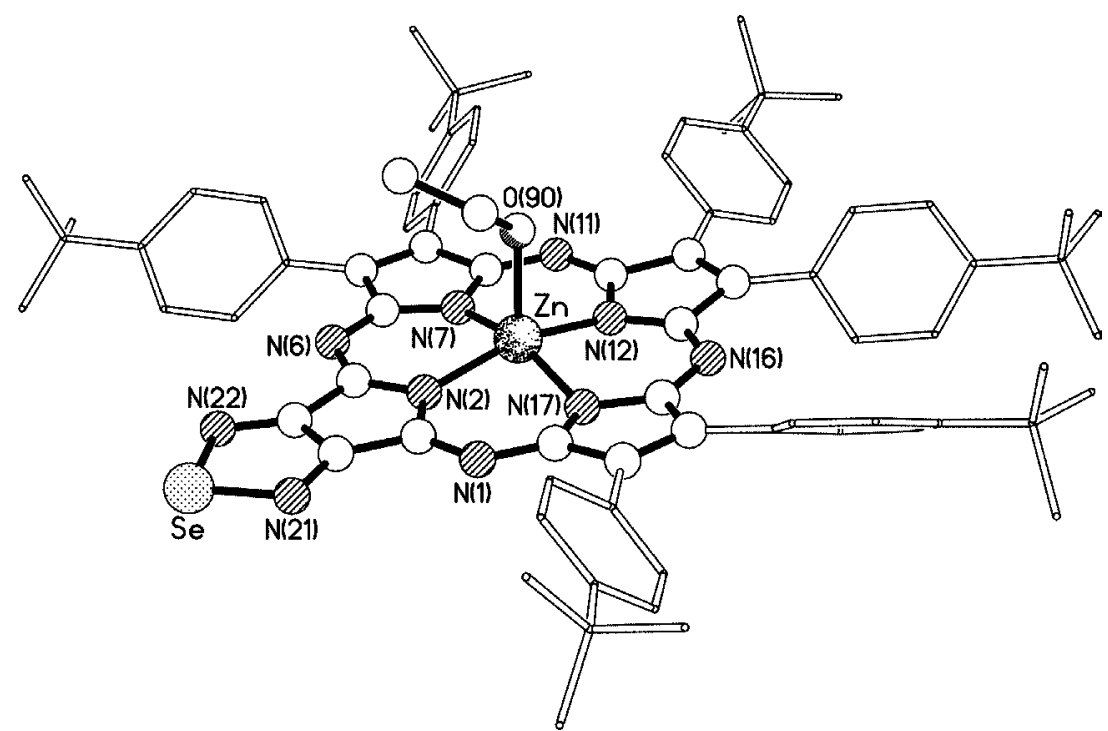

Fig. S13 The molecular structure of the ethanol-coordinated complex (I) present in the crystals of $\mathbf{3 b}$. 


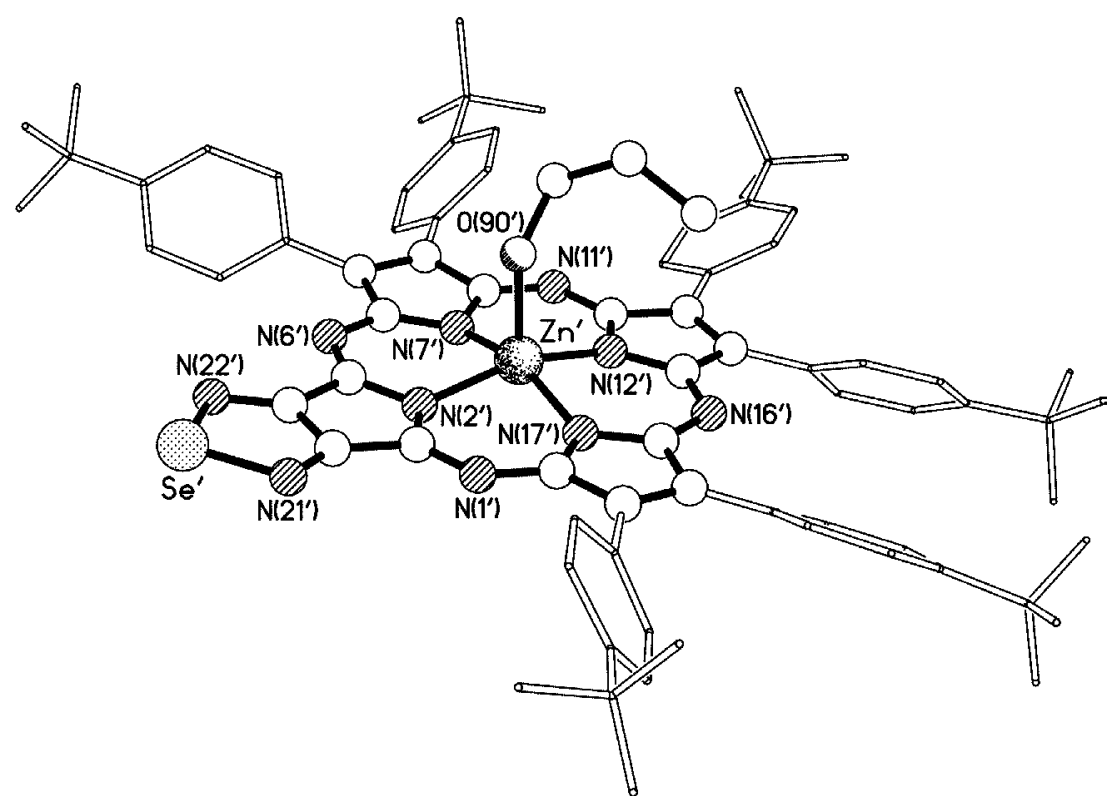

Fig. S14 The molecular structure of the $n$-propanol-coordinated complex (II) present in the crystals of $\mathbf{3 b}$.

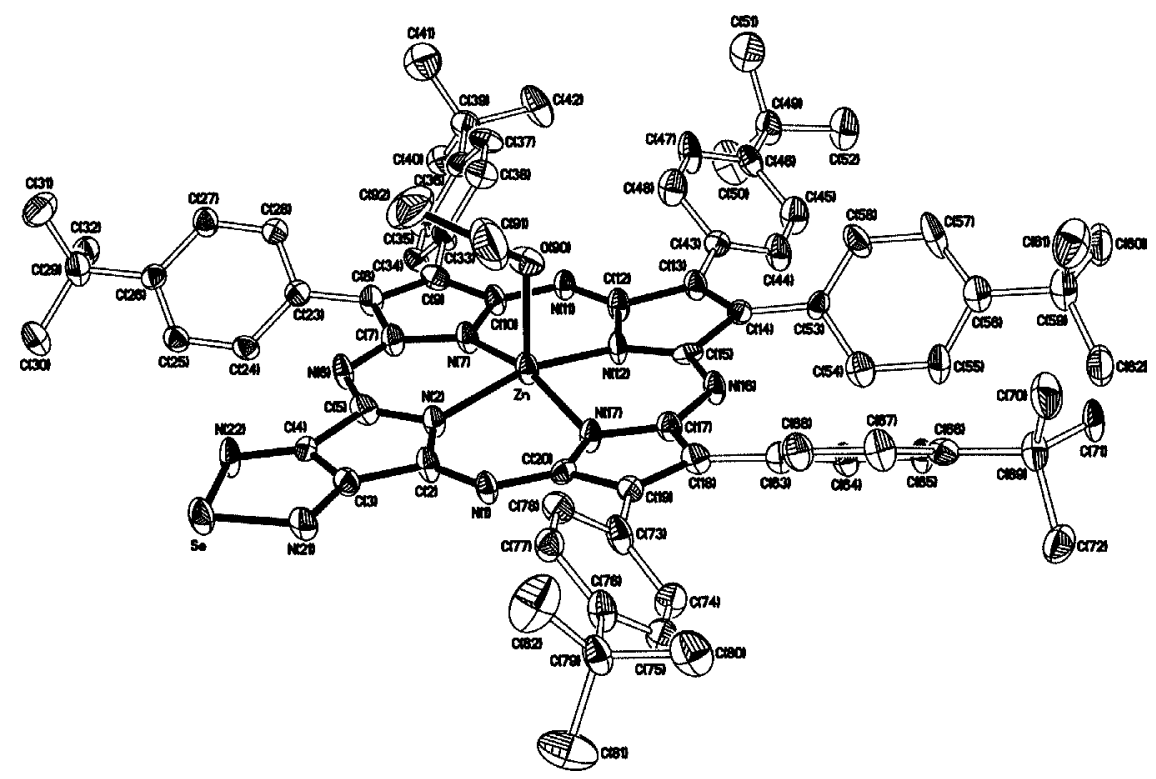

Fig. S15 The molecular structure of the ethanol-coordinated complex (I) present in the crystals of $\mathbf{3 b}$ ( $15 \%$ probability ellipsoids). 


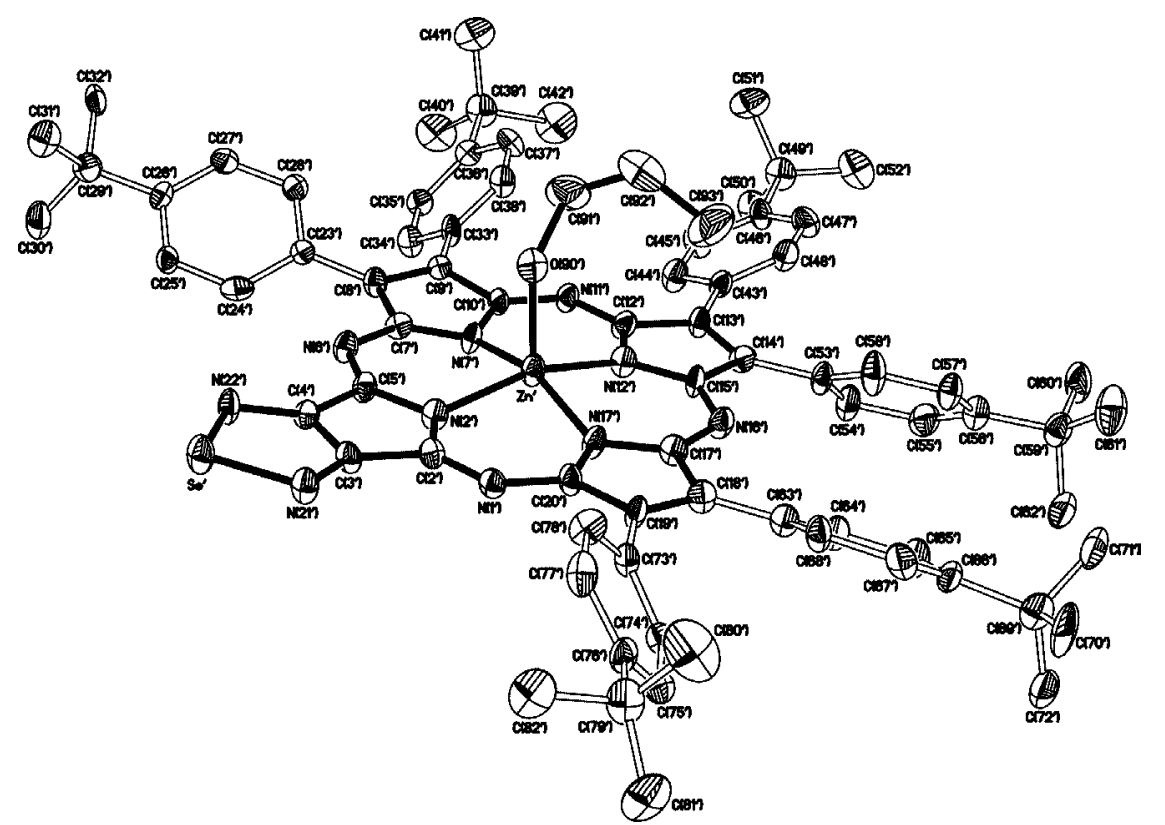

Fig. S16 The molecular structure of the $n$-propanol-coordinated complex (II) present in the crystals of $\mathbf{3 b}$ ( $15 \%$ probability ellipsoids).

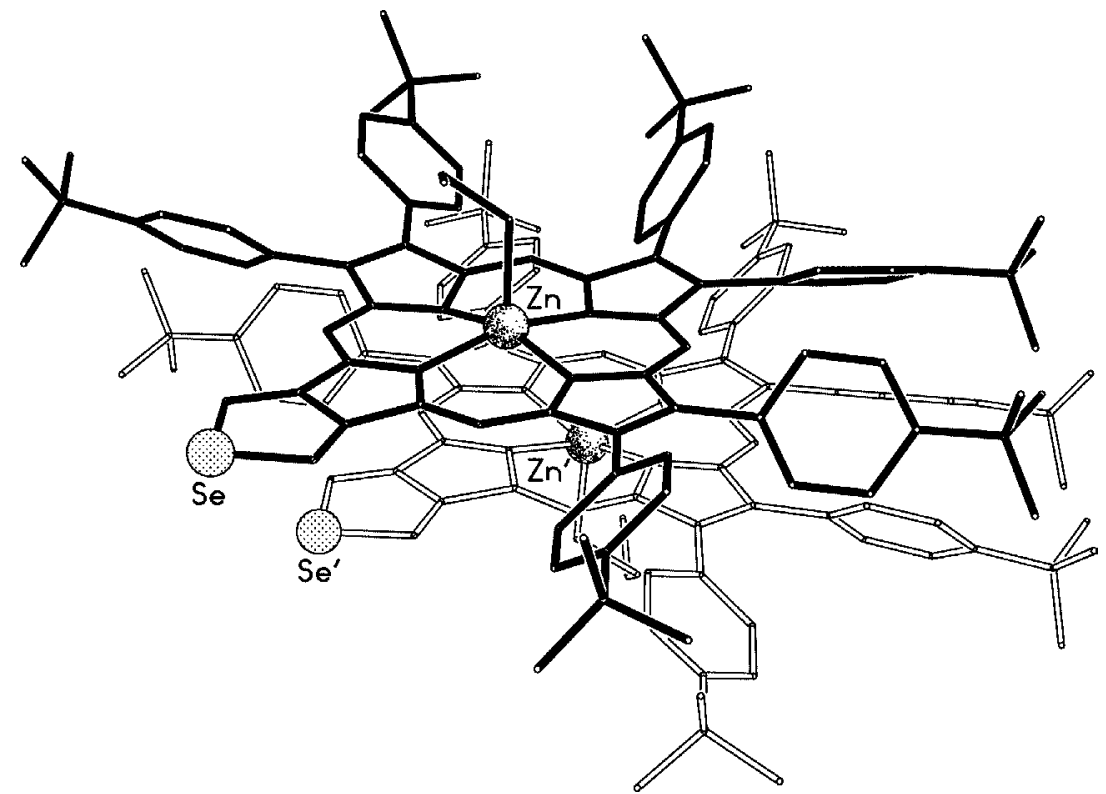

Fig. S17 The back-to-back stacking of the ethanol and $n$-propanol coordinated complexes (I and II) present in the crystals of $\mathbf{3 b}$. 


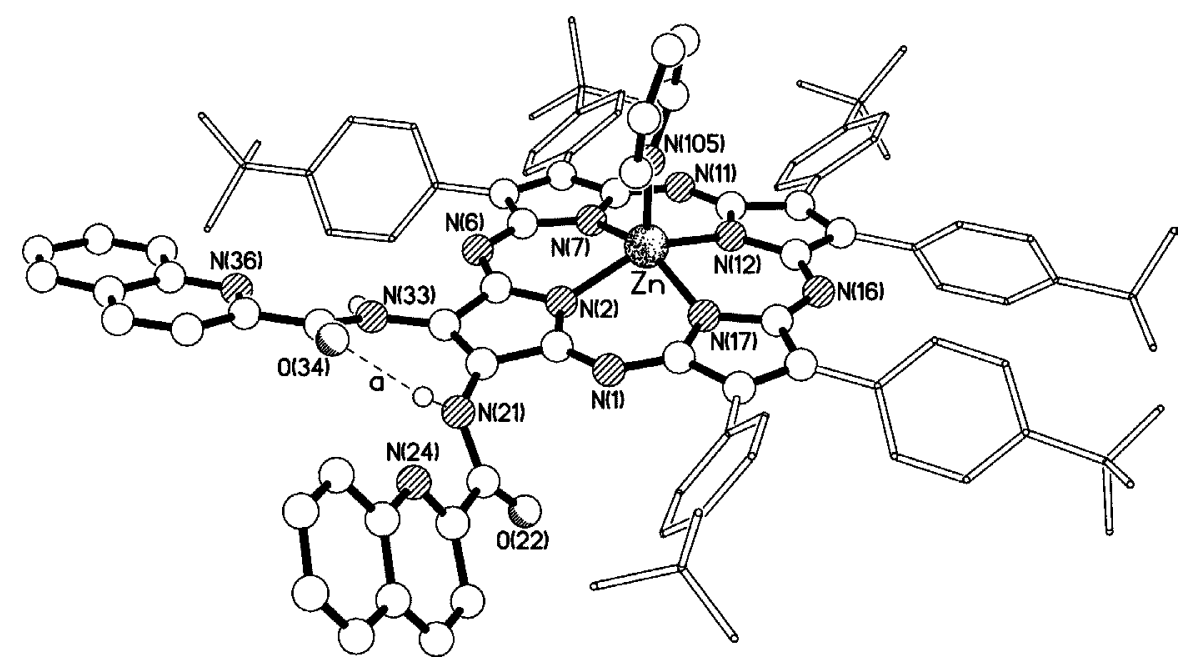

Fig. S18 The molecular structure of the pyridine-coordinated complex (I) present in the crystals of $\mathbf{1 4 b}$. The $\mathrm{N}-\mathrm{H} \cdots \mathrm{O}$ hydrogen bond (a) has $\mathrm{N} \cdots \mathrm{O} 2.658(9) \AA$, $\mathrm{H} \cdots \mathrm{O} 2.03 \AA$ and $\mathrm{N}-\mathrm{H} \cdots \mathrm{O} 126^{\circ}$.

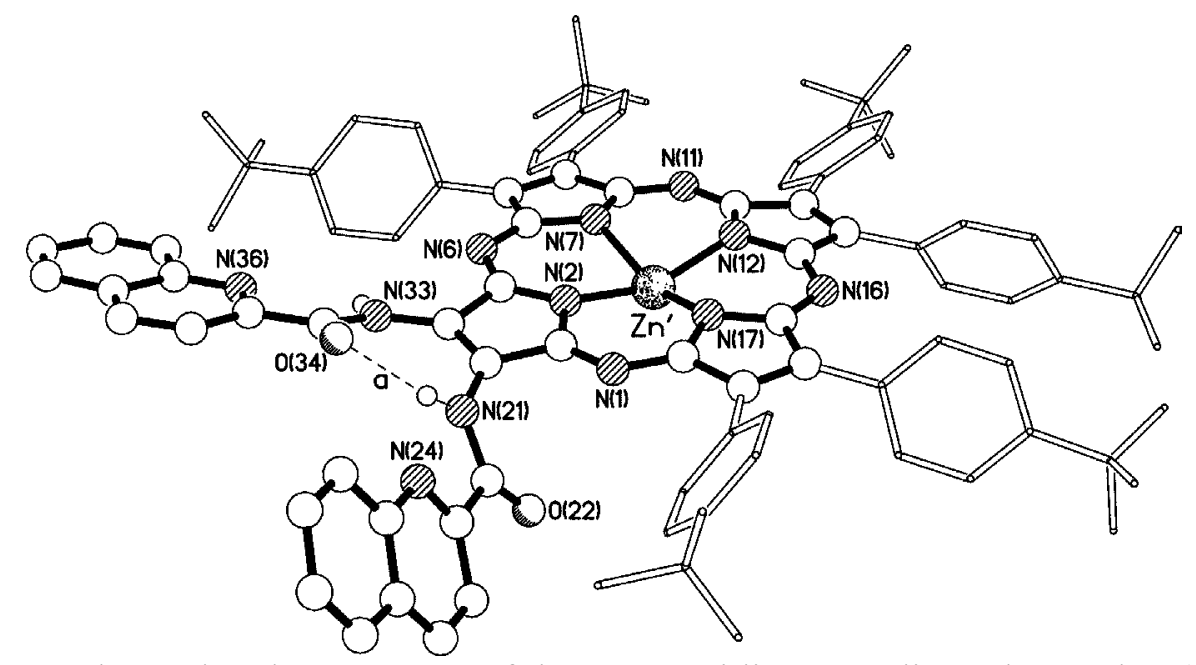

Fig. S19 The molecular structure of the non-pyridine-coordinated complex (II) present in the crystals of $\mathbf{1 4 b}$.

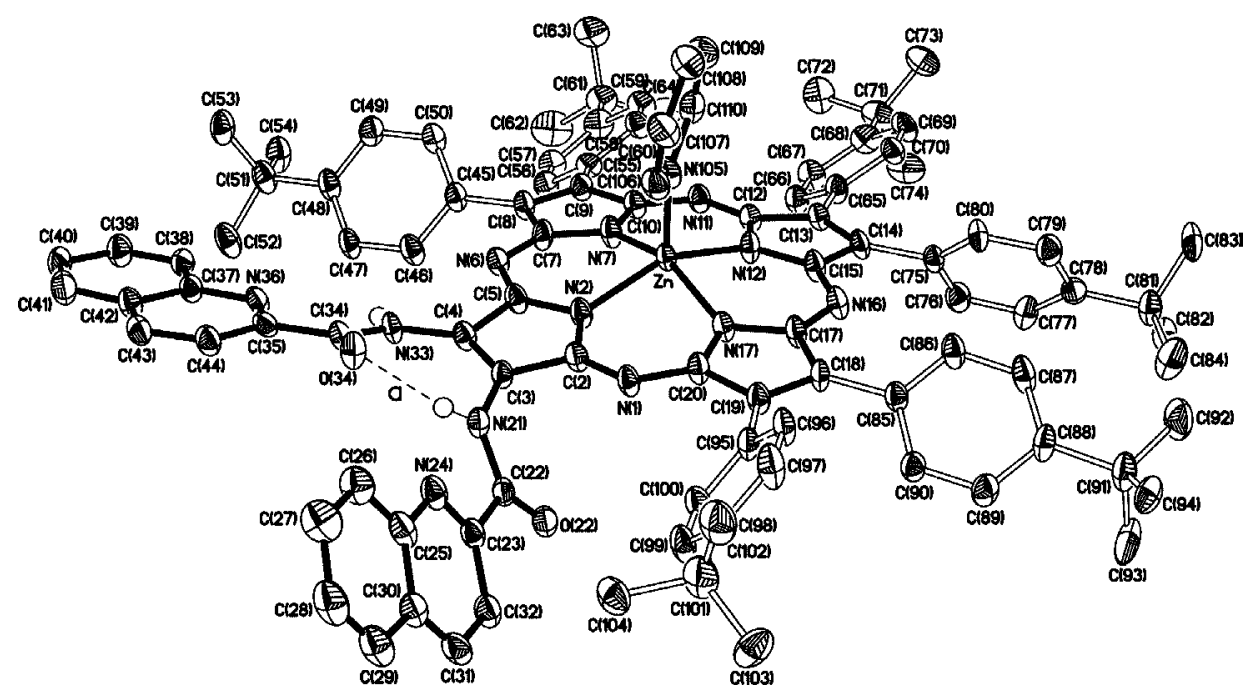

Fig. S20 The molecular structure of the pyridine-coordinated complex (I) present in the crystals of $\mathbf{1 4 b}$ ( $20 \%$ probability ellipsoids). 


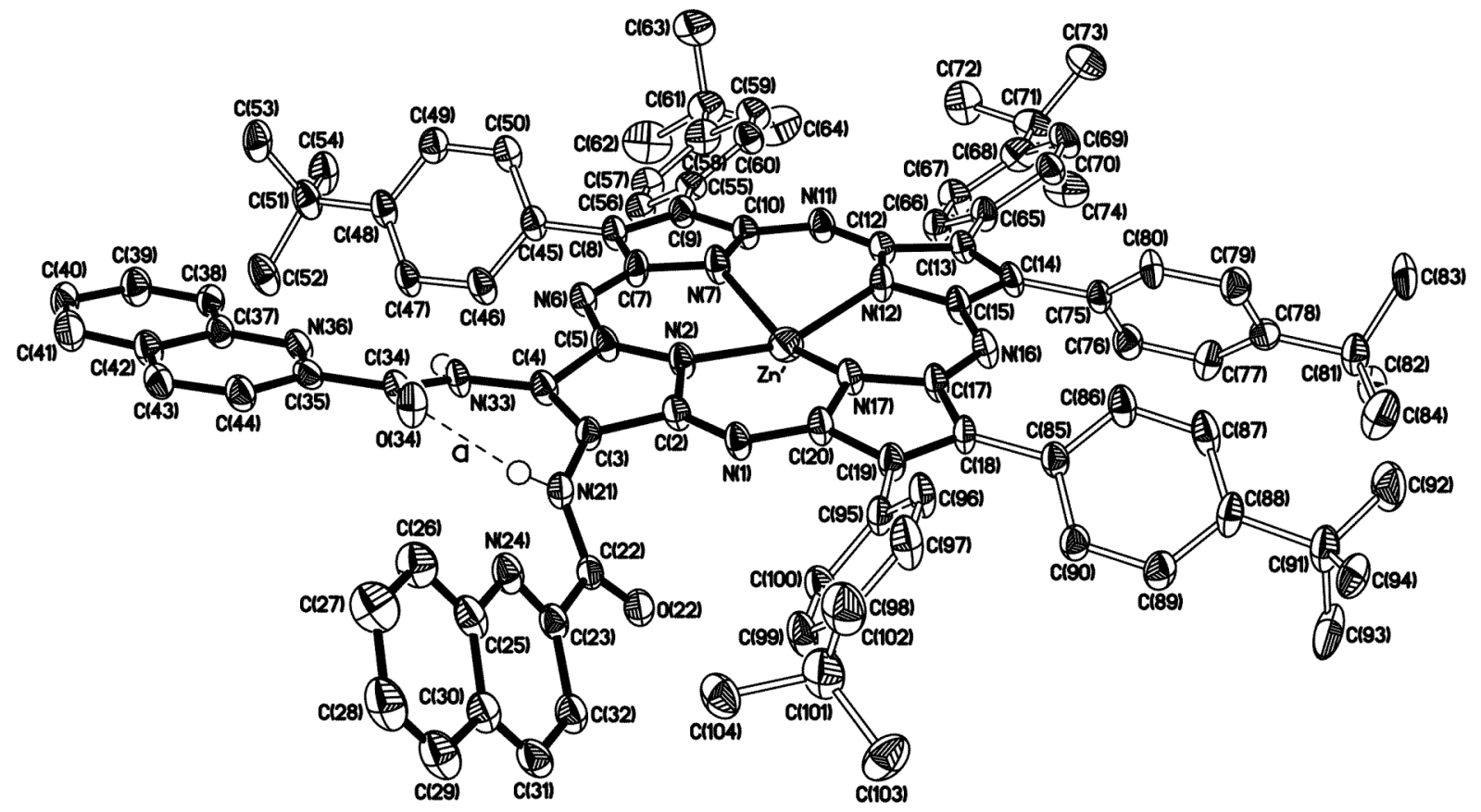

Fig. S21 The molecular structure of the non-pyridine-coordinated complex (II) present in the crystals of $\mathbf{1 4 b}$ ( $20 \%$ probability ellipsoids). 